\title{
Bolívar y su propuesta constitucional de 1826
}

\section{Juan Carlos Morón Urbina}

"[...] Bolívar vio, desde su prodigiosa altura intelectual, esta dicotomía entre las teorías y las realidades, que va a dominar durante más de un siglo la historia político-constitucional de Iberoamérica. Quiso mediar en medio de las fuerzas dispares e insertarlas en unas estructuras viables. Quiso hacer ver a los políticos la fuerza social de los militares, y a los abogados la necesidad de formas constitucionales realistas; intentó crearse fuerzas militares adictas, incluso utilizando ampliamente a oficiales voluntarios extranjeros, y reservarse, como Presidente, la administración de la poderosa palanca que suponía el distribuir a los militares las haciendas confiscadas a los realistas (sistema inaugurado con gran eficacia con Páez). Quiso, en fin, adelantándose a su tiempo, establecer la continuidad entre el antiguo y el nuevo régimen, logrando una independencia sin revolución, un gobierno fuerte y eficiente, una organización continental y estable, un sistema capaz de absorber los cambios en una evolución armónica, sin sacudidas demasiado fuertes. A ello consagró un pensamiento político genial, que no por haber sido inaceptado en su tiempo ha perdido una fecundidad, tal vez hoy mayor que nunca. Pero no era posible entenderlo sin situarlo en este contexto de las fuerzas que intentó, en vano, dominar; legitimidades rotas, guerra civil ilimitada, ideólogos exaltados y caudillos indomables [...]". (Manuel Fraga Iribarne; "La evolución de las ideas de Bolívar sobre los Poderes del Estado").

\section{Introducción}

Con vigencia formal desde el 09 de diciembre de 1826 hasta el 11 de junio del año siguiente y escasa eficacia real en el país, la Constitución 
peruana preparada por el Libertador Simón Bolívar reúne características propias de contenido y sentido -dentro de la proyección americana del pensamiento bolivariano-, que la individualizan dentro de la Historia Constitucional del Perú.

Como apreciaremos a continuación, este texto constitucional ha congregado en torno a él las opiniones más diversas de quienes han abordado la evolución de las ideas políticas e institucionales en nuestro país; desde la hipérbole más comprometida hasta la crítica más ácida que ha motivado Carta alguna en nuestra existencia.

Entre las críticas más adversas expuestas por los juristas nacionales resalta la de Toribio Pacheco ${ }^{1}$, quien considerando a Bolívar «el más grande déspota de los tiempos modernos", nos advierte que su texto constitucional:

"[...] en su conjunto y en sus más importantes disposiciones aparece como un plagio ridículo de la Constitución francesa del año II y decimos ridículo porque ni Bolívar, a pesar de su prestigio, contaba con los mismos elementos que el Cónsul Bonaparte para la duración de su obra, ni la sociedad peruana se parecía en nada a la francesa de esa época $[\ldots]$ ".

Sacando de esto una muy triste consecuencia para el Libertador de la América, y es que:

«[... no conocía el país en donde se hallaba y que, a pesar del vasto genio que comúnmente se le atribuye, caía frecuentemente bajo el influjo de ilusiones que, más de una vez, le produjeron amargos desengaños».

Dentro de esa misma posición crítica aunque moderada por el tiempo, encontraremos a Víctor Andrés Belaunde ${ }^{2}$-calificado por Fraga como el más profundo y fino intérprete del pensamiento político de Bolívar-, quien opina que el Libertador no acertó en la formulación de sus propósitos en esta Constitución, puesto que:

1 Toribio Pacheco; “Cuestiones constitucionales», Editorial Grijley. 1996, pp. 77 y 81 .

2 Víctor Andrés Belaunde; “La constitución vitalicia”. En: Mercurio Peruano, Año XI, Volumen XVII N 117. Marzo 1928. 
"Bolívar quiso realizar el milagro de reunir las cualidades de todos los sistemas; en realidad lo que hizo fue reunir todos sus defectos: el absolutismo del régimen vitalicio, la agitación demagógica de las asambleas electorales, los inconvenientes del centralismo y de la federación».

Por otro lado, Antonio Leocadio Guzmán ${ }^{3}$-cercano colaborador de Bolívar y glosador coetáneo de aquella Constitución- afirma hiperbólicamente:

\begin{abstract}
«[...] Esta no es sólo la Constitución de Bolivia, no es sólo una Constitución, sino el resumen de todo lo bueno que los hombres han sabido en la ciencia de gobierno; y el germen de una felicidad inmensa, que se desarrollará en medio de las sociedades que tengan la dicha de adoptarla. Jamás a mi entender, en el discurso de tantos siglos que ha que existe el género humano, se le ha ofrecido una producción de igual importancia ni de valor igual», y concluye sentenciando que "Bolívar al concebir y publicar este proyecto, se ha colocado en medio de dos mundos, ha sacado del uno lo más sublime de la libertad y del otro lo más sólido del Gobierno».
\end{abstract}

3 Antonio Leocadio Guzmán; “Ojeada al proyecto de Constitución que el Libertador ha presentado a la República Bolívar" Imprenta Republicana. Lima, 1826; pp. 4 y 10. Obra de cincuenta y dos páginas publicada en su tiempo para divulgar el proyecto de Carta y afianzar su aprobación nacional, lo cual le valió ser distribuida oficialmente por el Gobierno entre los Colegios Electorales. Es necesario revalorizar la importancia histórica de este personaje venezolano en el pensamiento político de Bolívar puesto que en los momentos claves del proceso integrador y de la proclamación de la dictadura bolivariana en Guayaquil, Panamá y Venezuela desempeñó el rol de comisionado personal del Libertador, llevando mensajes orales a líderes como el general Toro, Montilla, Padilla y José, Antonio Páez. Precisamente en una carta -la cual ruega se mantenga en absoluto secreto- dirigida por el Libertador a este último el 15 de noviembre de 1826, le diría: "Guzmán debe haber visto a Ud.; no dudo que le haya descubierto hasta el fondo de mi corazón; él lo ha visto hasta en sus últimos repliegues; lo ha visto todavía más de lo que en día es». En Hernández Sánchez Barba, "Simón Bolívar Discursos, proclamas y epistolario político" pp. 318 y 319. Para un análisis de la historia de este personaje puede leerse con provecho Guzmán: elipse de una ambición de poder (609 pp.) de Ramón Díaz Sánchez, Ediciones del Ministerio de Educación Nacional -Dirección de Cultura y Bellas Artes-. Caracas, Venezuela. 1950. 
Por su parte, el estudioso Gustavo Adolfo Otero ${ }^{4}$ exalta este proyecto constitucional afirmando que:

"[...] la Constitución de Bolivia se ofrece ante la mirada de la historia continental como una de las fuentes más llenas de atractivos para la investigación, por su doble contenido de jurídico y por su trascendencia de proyección americana. Si estos dos aspectos no fueran bastantes para inquietar al espíritu, hay uno de gran sugestión psicológica, y es que esta Constitución de Bolívar, fue la piedra de sacrificio del Libertador".

También tenemos en este repertorio de pareceres, la equilibrada posición de don Lizardo Alzamora ${ }^{5}$ para quien:

«La nueva Constitución, a pesar de sancionar algunos avances democráticos en materias generales sobre la de 1823, tenía un profundo tono aristocrático y jerárquico. La vitalicidad del Presidente y la de los Censores copiaba la organización napoleónica, que muchas veces imitó Bolívar, a pesar de lo que confesaba a su amigo Lacroix y consta en el famoso diario de Bucaramanga».

Finalmente, tenemos aquellos pareceres que siguen la objetividad necesaria otorgada por la serenidad del tiempo y el desapasionamiento inherente al jurista. En primer lugar, la justa consideración de Manuel Vicente Villarán, para quien:

«Puede sostener honroso paralelo la Constitución ideada por Bolívar con su prototipo francés al que, en cierto modo, mejora y supera. Ambas concepciones son, sin duda, erróneas como planes permanentes y para situaciones normales. [...] Para realizar este anhelo, Bolívar -no hay que ocultarlo- quiso, como Napoleón, estabilizar el gobierno en su persona, a fin de contener las inminentes borrascas de la anarquía y preparar dentro del orden una nueva era. Pudo hacerse monarca y rehusó por convicción, por prudencia y por orgullo. Pudo hacerse

4 Gustavo Adolfo Otero; «Bolívar y Bentham». En: Historia Revista de Cultura. Enero-Junio 1944, Volumen Segundo.

5 Lizardo Alzamora Silva; La evolución política y constitucional del Perú independiente. Universidad Nacional Mayor de San Marcos, Facultad de Derecho, p. 27. 
dictador perpetuo y prefirió las vías de la Constitución. Pudo en fin practicar el porfirismo, con reelecciones sucesivas de grado, por fuerza o por intriga y optó por el camino franco y audaz de la Presidencia vitalicia. Dejó con ello una lección magnífica de sinceridad y valor moral; pero cometió un error de táctica política que produjo su ruina ${ }^{6}{ }$.

Por su parte, la consideración análoga de José Pareja Paz-Soldán ${ }^{7}$ en el sentido que:

«Se ha querido ver en la Presidencia vitalicia de 1826 una forma camuflada de la Monarquía. Esta apreciación es totalmente injusta. Ya hemos dicho que Bolívar profesó un republicanismo sincero e indestructible. Fue toda su vida un republicano ciento por ciento. Lo fue por convicción sincera, porque intuía claramente que ese era el sentido invencible de la revolución americana y porque conocía con exceso, a los hombres, la realidad y el camino de América. [...] Al amparo de su inmenso prestigio nacional y de su gloria, el Libertador intentó crear una forma de gobierno que estabilizara el estado, alejase la anarquía y preparase la educación política del pueblo [...]. Bolívar pudo hacerse monarca y rehusó [...]. Pudo hacerse dictador perpetuo y prefirió la vía constitucional. Pudo mantenerse indefinidamente en el poder mediante sucesivas y forzadas elecciones y optó por el camino fresco y audaz de la Presidencia vitalicia que a su manera de ver, habría preparado dentro del orden, la nueva era. Chocó con la incomprensión de todos. Y fracasó. Porque no quiso entender que América hispana al advenir a la vida independiente, tenía que rendir tributo inevitable al caudillaje y a la anarquía».

Por su parte, el constitucionalista español -siempre preocupado por el devenir constitucional americano- Fraga Iribarne ${ }^{8}$ al exponer su parecer sobre esta Carta afirma:

6 Manuel Vicente Villarán; Páginas escogidas. Lima, 1962; p. 30 y ss.

7 José Pareja Paz Soldán; Derecho constitucional peruano y la Constitución de 1979. Apreciaciones y comentarios. Tercera edición. Ediciones Justo Valenzuela V. E.I.R.L. p. 46 y s. Cabe anotar que el mismo texto con algunas imperfecciones de impresión fue planteado en su obra "Las constituciones del Perú» (exposición crítica y textos). Ediciones Cultura Hispánica, Madrid 1954; pp. 167 y siguiente.

8 Manuel Fraga Iribarne; "La evolución de las ideas de Bolívar sobre los Poderes del Estado". En: Revista de Estudios Políticos No 117-118; mayo-agosto, año 1961. 
«Más que el texto mismo, la velocidad y los procedimientos que se utilizaron para implantarlo, dañaron a la nueva Constitución [...]. En los países que él había libertado, los "bolivianos" eran muchos, por lealtad personal al Libertador; por la preocupación que aún inspiraban España, la Santa Alianza y el Brasil; por el ejemplo de la anarquía ya existente en México, Buenos Aires y Chile, y por el temor del fracaso de la República pura y a la sublevación de las razas, que tanto temía el propio Bolívar. Pero aún eran más los desconfiados, que al final se salieron con la suya».

Finalmente, en una reciente obra de publicación póstuma, Luis Alberto Sánchez ${ }^{9}$ al referirse al pensamiento constituyente de Bolívar afirma con el peso de su autoridad que:

«Los enemigos del Libertador pusieron el grito en el cielo contra sus "ambiciones napoleónicas". En verdad no era más que su fe en la quimera de la unidad continental y su lucha enérgica contra el peligro de la anarquía. Deseaba que las nacientes repúblicas superaran sin trastornos sus primeras enfermedades de crecimiento. Sentía la imperiosa necesidad de ser "dictador a pesar suyo" si fuere menester [...]". Para concluir afirmando comprensivamente "Era en verdad la mejor Constitución que podía hacerse».

Esta síntesis de pareceres encontrados provenientes de los más preclaros estudiosos de nuestro constitucionalismo, nos advierten de lo contradictorio que ha sido la consideración de la historia constitucional peruana con la Constitución preparada por Bolívar. En verdad, como primera aproximación informativa al tema, cabe resaltar que la estructura sui generis de los poderes del Estado, y, en particular, la del poder ejecutivo ha ocupado interés preferente de la crítica especializada concentrando su atención; de suerte tal, que ha impregnado cualquier consideración favorable o desfavorable, cargando de emotividad y apasionamiento el análisis.

Lo cierto es que no es un episodio de nuestra historia constitucional de fácil análisis, ya que congrega en sí características excepcionales en nuestro país y difícilmente reproducibles:

9 Luis Alberto Sánchez Sánchez; A Bolívar. Instituto Luis Alberto Sánchez, 1997 , p. 168. 
a) Haber sido una Constitución otorgada por la autoridad del Libertador y no pactada como han sido todas las demás Cartas en nuestro país;

b) Inexistencia de documentos sobre los antecedentes y del proceso para la gestación de sus preceptos, aunado a la carencia de una exposición de motivos más o menos amplia que permita a los analistas conocer la razón esencial de su articulado, salvo el denominado "Discurso" que es bastante general; todo lo cual obliga a acudir a fuentes indirectas como las cartas del Libertador o de otros personajes de la época;

c) Ser un proyecto constitucional típicamente proveniente de la autoridad unipersonal de un hombre de acción como Bolívar, cuya figura y actuación política de por sí genera adhesiones y repulsas a sus analistas ${ }^{10}$

d) Haber rodeado su proceso generativo de un halo de misterio que dificulta conocer a priori por ejemplo, las razones de los cambios entre los proyectos sometidos a Bolivia y a Perú, que contrariamente a lo generalmente aceptado, no fueron idénticos;

e) La pretensión consciente del texto por perfilarse como una síntesis particular entre diversas corrientes constitucionales y de ideologías en boga en la época sin seguir un patrón único, que por ejemplo, le otorga el privilegio de concentrar en su estructura el poder neutro (con la presencia de la Presidencia vitalicia) con el poder conservador (en el Senado conservador) así como ser la única que atribuye facultades activas propias en asuntos gubernativos al cargo de Vicepresidente.

Pero un aspecto que resulta importante tomar conciencia es analizar si en el pensamiento bolivariano esta Carta se trataba de una Constitución de transición -en los términos planteados por Alberdi-, esto es que fue como un medio para madurar el proceso de síntesis durante una

10 Como bien resalta Fraga Iribarne debemos anotar la idea de que Bolivar expone en la Constitución de 1826 su pensamiento absoluto, como lo testimonia el propio Libertador cuando escribió a Santander el 27 de diciembre de 1825 desde Chuquisaca, "[...] A propósito, estoy haciendo una constitución muy fuerte y muy bien combinada para este pais [...]. En general, la constitución esta muy bien trabada y el discurso que dará, para probar su utilidad será muy fuerte. No dudo que será mejor que el otro de Angostura, pues ya no estoy en estado de transigir con nadie". Jorge Pérez Concha; Pensamiento político de Bolívar p. 83. 
etapa de tensiones de crisis política, con miras a una estabilidad futura; o, si contrariamente, pertenecía a las denominadas Constituciones definitivas que se suelen establecer en momentos de consolidación de alguna ideología, grupo social, o luego de concluido un proceso de crisis.

\section{Proceso histórico del proyecto constitucional del Libertador para la naciente República de Bolivia}

\subsection{Perspectiva continental del proyecto: Federación Boliviana o de los Andes}

Analizar la importancia de la Constitución peruana de 1826 resulta imposible sin referirla a la Constitución boliviana del mismo año, de igual modo como ambas no pueden comprenderse a plenitud dentro del pensamiento del Libertador sin hacer referencia a su proyecto panamericano.

Dichos textos normativos pretendían constituir una fase dentro de un proceso de integración americana que Bolívar sólo llegó a iniciarlo, pero fue rápidamente desestabilizado. Dentro de dicho pensamiento, estos textos poseían una fuerte concepción federativa entre diversos Estados cuyo punto de conexión político sería la Carta constitucional homogénea en todos sus miembros, la Presidencia vitalicia federativa y un Congreso Panamericano electo proporcionalmente por cada Estado integrante: Bolivia, Perú y Colombia.

Tan luego concluido el proyecto de Constitución para Bolivia, el propio Libertador comunicó esta concepción en su carta de 12 de mayo de 1826 dirigida al General Antonio Gutiérrez de la Fuente, en la cual acerca de las voces que en Venezuela clamaban por el retorno al imperio ante la crisis generalizada que atravesaba y el temor que igual situación se proyectase a Perú, decía:

«Después de haber pensado infinito, hemos convenido entre las personas de mejor juicio y yo, que el único remedio que podemos aplicar a tan tremendo mal es una federación general entre Bolivia, el Perú y Colombia, más estrecha que la de los Estados Unidos, mandada por un Presidente y vicepresidente y regida por la constitución boliviana, que podrá servir para los Estados en particular y para la federación en general, haciéndose aquellas variaciones del caso. 
La intención de este pacto es la más perfecta unidad posible bajo una forma federal. El gobierno de los estados federales o particulares quedará al Vicepresidente con sus dos cámaras para todo lo relativo a religión, justicia, administración civil, economía y, en fin, todo lo que no sea relaciones exteriores y guerra. Cada departamento mandará un diputado al congreso federal y éstos se dividirán en las secciones correspondientes, teniendo cada sección un tercio de diputados cada república. Estas tres cámaras, con el vicepresidente y los secretarios de Estado, que serán escogidos en toda la república. El Libertador, como jefe supremo, marchará cada año a visitar los departamentos de cada Estado. La capital será un punto céntrico. Colombia deberá dividirse en tres Estados: Cundinamarca, Venezuela y Quito; la federación llevará el nombre que se quiera; habrá una bandera, un ejército y una sola nación. De cualquier modo que sea, es indispensable que se dé principio a este plan por Bolivia y el Perú, como que, por sus relaciones y situación local, se necesitan más una al otro. Después me será fácil hacer que Colombia adopte el único partido que le queda de salvación. Unidos el alto y bajo Perú, Arequipa será la capital de uno de los grandes departamentos que se formen a manera de los tres de Colombia [...]m. ${ }^{11}$

En otra misiva de la misma fecha, pero dirigida al Mariscal Antonio José de Sucre -quien en ese momento aparentemente se retiraba de la actividad gubernativa- confiesa este mismo objetivo aunque aporta datos complementarios y algunos de ellos ciertamente incompatibles sobre su visión de esa futura federación e incluso con la Carta boliviana:

«Se está imprimiendo hoy mismo mi constitución boliviana; ésta debe servir para los estados en particular y para la federación en general, haciéndose aquellas variaciones que se crean necesarias. Ud. debe dar el ejemplo con Bolivia a esta Federación, adoptando desde luego la constitución que ha recibido una perfección casi inesperable [...]. La intención de este pacto debe ser la más perfecta unidad posible bajo una forma federal. El gobierno de los estados particulares quedará al presidente y vicepresidente con sus cámaras, con todo lo relativo a la religión, justicia, administración civil, economía, y, en fin, todo lo que no sea relaciones exteriores, guerra y hacienda nacional. El gobierno

11 Simón Bolívar, Escritos Políticos, p. 153 y ss. Alianza Editorial. 1990. 
general se compondrá de un presidente, vicepresidente y tres cámaras para manejar la hacienda nacional, la guerra y las relaciones exteriores. Cada departamento de las tres repúblicas mandará un diputado al gran congreso federal, y ellos se dividirán en las tres secciones correspondientes, teniendo cada sección un tercio de diputados de cada república. Estas tres cámaras, con el vicepresidente y los secretarios de estado (que serán escogidos éstos en toda la república) gobernarán la federación. El Libertador, como jefe supremo, marchará cada año a visitar los departamentos de cada estado. La capital será un punto céntrico como Quito o Guayaquil; Colombia deberá dividirse en tres estados, Venezuela, Cundinamarca y Quito; uno tomará el nombre de Colombia, que probablemente será Cundinamarca; la federación llevará el nombre que se quiera, pero sería probable que fuese Boliviana. Habrá una bandera, un ejército y una nación sola. Heres dice que es mejor que haya dos naciones como Bolivia compuesta del Bajo y Alto Perú, y Colombia compuesta con sus partes constituyentes. Que yo sea el presidente de ambas naciones y haga lo mismo que con una. El consejo de gobierno quiere la reunión de las tres repúblicas, como he dicho antes, y Pando se inclina a uno y otro partido [...].

De cualquier modo que sea, creo indispensable el que se dé principio a este plan por Bolivia y el Perú, y todavía crea más indispensable el que Ud. conduzca los negocios de ese país hasta que yo vuelva a darle una dirección general a esta federación. Entonces no faltará algún amigo a quien convenga favorecer para esa presidencia. El general Santa Cruz servirá éste del Perú a menos que se desagraden de él, lo que no espero, porque él es bastante agradable y sagaz". ${ }^{12}$

En ambas misivas, que fueron datadas en la misma fecha y tan luego concluida la formulación de su proyecto constitucional resalta la sólida proyección panamericana del documento, que trascendía el alcance de un Estado; pero, no podemos dejar de reparar en las diferencias orgánicas que claramente fluyen al comparar su organización propuesta. Sobre todo si nos detenemos en contrastar la noción de cómo se estructuraría el comando de cada estado federado o en el tema de la distribución de competencias entre el gobierno nacional y el de nivel federal. Lo cual aunado a la insuficiente información acerca del plan integral de la Federación, nos anima a afirmar que para esta época no

12 Simón Bolívar, Escritos Políticos. pp. 147 y 151. Alianza Editorial. 1990. 
se encontraba uniformemente determinado o no se deseaba su temprana divulgación.

En una carta ulterior dirigida a Páez el 8 de agosto de 1826 el Libertador reconoce estas circunstancias, pero tampoco nos aporta mayores criterios para dilucidarlos; en ella le dice:

«[...] Yo desearía que con algunas modificaciones se acomodara el Código boliviano a Estados pequeños enclavados en una vasta Confederación, aplicando la parte que pertenece al Ejecutivo al gobierno general y el poder electoral a los Estados particulares».

Lamentablemente las fuentes directas conocidas resultan insuficientes para conocer en lo orgánico las bondades integrales de este proyecto constitucional panamericano. Por este objetivo panamericano es que el proyecto de Constitución fue difundido a los demás Estados involucrados a través de los principales colaboradores de Bolívar: Venezuela por medio del General Páez (Carta de 26 de mayo de 1826), Santander en Colombia (Carta de 30 de mayo de 1826), Joaquín de Olmedo para su conocimiento en Europa (Carta de 02 de junio de 1826), entre otros.

Pero, primero había que poner en vigencia la Carta Constitucional en Bolivia, luego, en Perú y después en Colombia.

\subsection{Pensamiento bolivariano sobre la independencia de Bolivia}

Con bastante razón, menciona V. A. Belaunde ${ }^{13}$ que:

«Por mucho tiempo se creyó que la separación de las provincias del Alto Perú, fue obra exclusiva de la voluntad del Libertador, inspirada en el plan de crear dos naciones débiles frente a la gran Colombia, cuya hegemonía deseaba conservar a todo trance. Estudios recientes han destruido esa creencia. Existía evidentemente en el antiguo territorio de la audiencia de Charcas un vivo sentimiento nacionalista».

En cuanto a Bolívar, es conocido el conflicto que le originó con Sucre, la decisión de convocar a la Asamblea constitutiva; por lo que su

13 Víctor Andrés Belaunde; «La Constitución vitalicia». Mercurio Peruano, Año XI, Volumen. XVII, Nº 117; Marzo 1928; p. 161 y ss. 
actitud ante los hechos consumados fue intervenir y luego plantear la federación con Perú. Esta situación la veremos cuando en su Carta al General Santander de 23 de febrero de 1825 fechada en Lima, le indica:

«[...] Yo pienso irme dentro de diez o doce días al Alto Perú a desembrollar aquel caos de intereses complicados que exigen absolutamente mi presencia. El Alto Perú pertenece de derecho al Río de la Plata, de hecho a España, de voluntad a la independencia de sus hijos que quieren su estado aparte, y de pretensión pertenece al Perú, que lo ha poseído antes, y lo quieren ahora. Hoy mismo se está tratando en el congreso de éste, y no sé lo que resolverán. Yo he dicho mi dictamen a todo el mundo, haciendo la distribución en los mismos términos que arriba quedan indicados. Sucre tiene la orden de tomar al país por cuenta de la independencia y del ejército libertador, y creo que el derecho debe ventilarse en la asamblea del istmo. Entregarlo al Río de la Plata, es entregárselo al gobierno de la anarquía y someter a los habitantes, a las tropas de Olañeta, que actualmente lo poseen, y que entrarán por algún arreglo pacífico. Entregarlo al Perú es una violación del derecho público que hemos establecido, y formar una nueva república como los habitantes desean en una innovación de que yo no me quiero encargar y que sólo pertenece a una asamblea de americanos».

\subsection{Encargo del constituyente boliviano al Libertador para presentar proyecto de Constitución}

El constitucionalista boliviano Ciro Félix Trigo $^{14}$, nos informa que la Asamblea deliberante de 1825 , que clausuró sus sesiones el 6 de octubre de ese año, dispuso para el 25 de mayo de 1826 la reunión de un Congreso General Constituyente y solicitó a Bolívar un proyecto de Constitución, que fue remitido desde Lima en el mes de junio de 1826, acompañado de un mensaje denominado «Discurso del Libertador al Congreso Constituyente de Bolivia». Difícil será determinar la plena espontaneidad de este encargo al Libertador o por lo contrario, su inducción a favor de sus proyectos federalistas.

Resulta sumamente importante resaltar que para este cometido la sesión secreta de la Asamblea deliberante de Bolivia realizada el 20 de

14 Ciro Félix Trigo; Las constituciones de Bolivia. Ediciones Cultura Hispánica; Madrid (España), 1957, p. 67 y ss. 
agosto de 1825, designa una Legación Parlamentaria integrada por Casimiro Olañeta y José María Mendizábal, a fin de que -entre otros aspectos-solicitara del Libertador un Proyecto de Constitución para el régimen político del naciente Estado. Dicho encargo lo cumplieron mediante sendas conferencias solemnes y secretas, de las cuales fluyó la aceptación del Libertador.

\subsection{Preparación del proyecto bolivariano y aprobación en la Repúbli- ca de Bolivia}

Recibido el encargo de elaborar la Constitución de la naciente Bolivia, el Libertador se abocó a desarrollar el proyecto. A juzgar por la correspondencia de la época, el proyecto fue preparado personalmente con inusitada rapidez, ya que hacia fines de ese mismo año (Cartas de 25 de setiembre - desde Oruro-y de 27 de diciembre de 1825 -desde la misma Chuquisaca-) informaba a Santander de tal labor y curiosamente de los lineamientos generales del contenido del proyecto que después sería presentado en la propuesta oficial. En la primera afirmaba acerca de su futura propuesta constitucional:

"[...] Pienso que ésta será fuerte y nueva, ligando las ventajas de las repúblicas de América [...] habrá algo de gobierno vitalicio y algo también de las libertades del federalismo. En fin, la cosa no dejará de tener sus amigos y sus enemigos».

Pero, es en la segunda misiva, donde transparenta con mayor amplitud sus líneas matrices:

"A propósito, estoy haciendo una constitución muy fuerte y muy bien combinada para este país, sin violar ninguna de las tres unidades y revocando, desde la esclavitud abajo, todos los privilegios. Diré, en sustancia que hay un cuerpo electoral que nombra al cuerpo legislativo; pide cuanto quiere el pueblo y presenta tres candidatos para jueces. prefectos, gobernadores, corregidores, curas y vicarios de los respectivos distritos. El cuerpo legislativo se divide en censores, senadores y tributos. Los departamentos del gobierno están divididos entre cada cámara para la iniciativa de las leyes. Pero con veto de las otras cámaras. El poder judicial es nombrado parte por el pueblo, y parte por el senado, pero con aprobación del congreso. 
El poder ejecutivo se compone de un presidente vitalicio que nombra todos los empleos de guerra, hacienda y relaciones exteriores: es inviolable. El vicepresidente es nombrado por el presidente con la aprobación del congreso: él es responsable de la administración con dos secretarios de estado y él es responsable de toda la administración. El Presidente nombra los empleados, pero no responde de su manejo, como el cuerpo legislativo hace las leyes, y el ejecutivo las cumple. El vicepresidente es el sucesor del presidente por muerte o por renuncia.

Los ciudadanos deben ser aquellos que tengan cualidades y habilidades pero no fortuna. El que no sabe escribir, ni paga contribución, ni tiene un oficio conocido, no es ciudadano.

En general, la constitución está muy bien trabada y el discurso que dar, para probar su utilidad será muy fuerte. No dudo que será mejor que el otro de Angostura, pues ya no estoy en estado de transigir con nadie $[\ldots]) .{ }^{15}$

Como se pude apreciar, las líneas matrices del proyecto se encontraban definidas en el pensamiento de Bolívar aún antes de su retorno a Lima, en aspectos fundamentales de su planteamiento como son: la del Presidente vitalicio, al tricameralidad, el liberalismo, la abolición de privilegios, el cuerpo electoral, la preponderancia del vicepresidente y requisitos para la ciudadanía.

Luego, el Libertador se retiró a Lima prometiendo entregarles la Constitución «más liberal del mundo» (Proclama de 01 de enero de 1826).

Todos los indicios seguidos por los historiadores establecen que en el Perú la labor de revisión del texto estuvo a cargo de una Comisión de expertos constituida por Hipólito Unanue, José María Pando y Tomás de Heres. Comisión que lamentablemente no dejó diario de debates o actas de sesiones para permitirnos analizar aspectos importantes sobre su proceso, alcances de su actividad y desentrañar la intención legislativa. Sin embargo, a juzgar por el contenido de la Carta antes mencionada remitida a Santander que revela una posición clara del Libertador acerca de los perfiles centrales de la propuesta, debemos inferir que la actividad de esta Comisión estuvo concentrada más en la revisión y ajustes, que propiamente en la elaboración del proyecto o postulado de ideas propias.

15 Jorge Pérez Concha; «Pensamiento político de Bolívar», pp. 75 y 76. 
Se trataban de personajes del entorno más íntimo del Libertador. A Unanue, Bolívar lo reconocería por sus conocimientos, versación intelectual y capacidad, de tal modo que lo consideraría para el cargo de Vicepresidente una vez instalado el régimen vitalicio (Carta al Mariscal Sucre de 12 de mayo de 1826). Por su parte, José María Pando era el hombre de leyes a quien Bolívar no le recorta halagos en sus misivas de la época (ver también su Carta al Mariscal Sucre de 12 de mayo de 1826) para resaltar su rectitud ${ }^{16}$. Finalmente, integraba esta Comisión Tomás Heres -de origen colombiano- quien era el militar encargado del Ejército Libertador y acompañante de Bolívar durante sus sucesivos viajes por Perú y Bolivia, quien serviría dentro de la Comisión como orientador político sobre la auténtica voluntad del Libertador.

El Libertador no pudo presentar personalmente el proyecto de su Constitución a Bolivia cual era su deseo, por cuanto el Congreso de Colombia no le otorgó el permiso correspondiente. Presentado el proyecto preparado por Bolívar en junio de 1826, fue sometido durante veinticuatro días a la Comisión de Negocios Constitucionales compuesta por los señores: Casimiro Olañeta, José María Urcullu, José Ignacio de Sanjinez, Manuel Molina, Mariano Callejo, Mariano Calvimontes, Mariano Guzmán, Pascual Romero y Antonio Vicente Seoane quienes le incorporaron algunas modificaciones de orden contextual y no esenciales, según ellos mismos confesaran:

«[...] No obstante la comisión se ha visto en la necesidad de hacer algunas pequeñas alteraciones en varios artículos del proyecto, confesando francamente que es mejor el texto original. Particulares circuns-

16 El aporte de José María Pando al proyecto debe haber sido más bien de revisión final que de elaboración misma por el factor temporal que aparentemente ha sido obviado por los historiadores. En efecto, el Libertador en su carta a Santander fechada en Lima, el 7 de abril de 1826 expresa: «[...] Espero a un tal Pando, que ha ido al istmo, para ponerlo en el ministerio de estado. Este caballero tuvo el mismo destino en Madrid en tiempo de las Cortes. Tiene mucha semejanza con Revenga y en todo es superior, porque ha estado siempre en Europa en la carrera diplomática. Su honradez, su energía y sus luces compiten entre sí; pero no es agradable ni amado, aunque es el primer hombre del Perú. Nació en Lima y tiene toda su familia aquí; mas no es conocido por haber estado siempre fuera. [...] Lo único que me retiene es la constitución de Bolivia: ya la tengo concluida y quisiera presentarla personalmente al congreso de aquel país. 
tancias del país y consideraciones de pública utilidad han determinado a ello. El Congreso Constituyente juzgará el valor y la fuerza de las razones que sus individuos han tenido para la redacción que se acompaña»."

La modificación más importante de esta Comisión fue incorporar el artículo $6 \$$ considerando como religión del Estado a la católica, apostólica y romana, con exclusión de todas las demás; ya que el texto original preparado por Bolívar conscientemente omitía consignar alguna disposición sobre esta materia, por cuanto siguiendo el parecer tolerante propio del liberalismo de Locke y Voltaire, manifestaba el discurso del Libertador a Bolivia:

«En una Constitución política no se debe prescribir una profesión religiosa; pues, según las mejores doctrinas acerca de las leyes fundamentales, las últimas sirven de garantía a los derechos civiles y políticos. Como la religión no pertenece a ninguno de éstos, es de otra naturaleza indefinible en el orden social y pertenece al orden intelectual. La religión es la ley de la conciencia. Toda ley sobre ella la anula, porque imponiendo la necesidad al deber, quita el mérito a la fe, que es la base de la religión. Los preceptos y los dogmas sagrados son útiles, luminosos y de evidencia metafísica; todos debemos profesarlos; más este deber es moral, no político».

Coetáneamente, en Bolivia, el Mariscal Sucre hizo observaciones al texto y planteó la primera crítica pública que se le conoce, según nos informa Otero en su mencionado estudio. El Mariscal expresaba en una crítica que el futuro inmediato boliviano se encargaría de darle la razón:

"De mi parte haré, confesión sincera que no soy partidario de la Constitución boliviana: ella da sobre el papel estabilidad al gobierno, mientras que de hecho le quita los medios de hacerse respetar».

17 Gustavo Adolfo Otero; "Bolivar y Bentham (Génesis de la Constitución Boiviana de 1826)". En: Historia Revista de Cultura N 6, Volumen Segundo. Enerojunio de 1944. Lima (Perú), p. 90. 


\section{Proceso histórico de la Constitución bolivariana en Perú}

\subsection{Entorno político-constitucional al proceso}

Mientras este proceso acontecía en Bolivia, bajo la vigencia parcial de la Carta de 1823, en Perú se suscitaba un conflicto sobre el alcance de los poderes conferidos por los electores a los representantes a Congreso que se encontraban ya reunidos para su Junta preparatoria.

Sucedía en primer lugar, que el Gobierno dispuso mediante aviso oficial insertado en la Gaceta de Gobierno (08.04.1826) que se le presentaran los poderes de los diputados reunidos para sus Juntas Preparatorias, argumentando ello para señalar el día y hora de la debida juramentación ${ }^{18}$. Luego de producida esta revisión, mediante Decreto (17.04.1826), dispuso que era indispensable renovar los poderes otorgados en las provincias de Lima, Arequipa, Condesuyos, Bolívar (La Libertad), Cusco, Lambayeque y Quispicanchi ya que a su criterio contenían deficiencias por no respetar la fórmula sacramental prevista en la Ley de elecciones.

Producido este impasse, el Congreso Nacional postergó sus sesiones, propiciando que cincuenta y dos congresistas dirigieran una petición al Libertador (21.04.26) en el sentido de analizar la necesidad de consultar al pueblo, tanto sobre la probable reforma total o parcial de la Carta de 1823, que había sido suspendida por el propio Congreso en aquellas materias incompatibles con el encargo conferido a Simón Bolívar para

18 La Constitución Política de 1823 (artículos $191^{\circ}$ y $192^{\circ} \$$ ) establecía que luego de concluida la guerra, debería ser ratificada o reformada por un Congreso General compuesto por los diputados de las provincias libres, a la cual los representantes debían asistir con poderes con una ucláusula especial que los autorice para ello». En vía de desarrollo legislativo, el propio Bolívar con fecha 3 de marzo de 1825 promulgó la «Ley reglamentaria de elecciones de diputados a Congreso, Senadores y Diputados departamentales conforme a la Constitución Política de la República Peruana" aprobada por el Congreso, que entre otros aspectos interpretaba (Art. $58^{\circ}$ ) que la reforma de la Constitución no tiene lugar, hasta que se determine por el Congreso la época de la reforma o alteración y, además, aprobada una fórmula sacramental a seguir por todos los colegios electorales para otorgar poderes a sus diputados, donde constaba expresamente su limitación a proponer cualquier derogación, alteración o modificación constitucional y viceversa la obligación de sus otorgantes a obedecer y

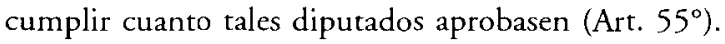


culminar la liberación de la patria ${ }^{19}$, así como sobre cuál es el magistrado supremo que la nación designaría para recibir el cargo de Bolívar. Aprobada dicha petición por el Consejo de Gobierno (27.04.1826), dispuso el censo de la población nacional y la convocatoria de los Colegios electorales (01.04.1826).

Luego de renovado el Consejo de Gobierno, bajo la presidencia de Andrés Santa Cruz e integrado por Unanue, José María Pando y José de Larrea y Loredo, dispuso (28.06.1826) que los prefectos convocaran a los colegios electorales para que se pronunciaran sobre el proyecto de Constitución y sobre la persona que debía ejercer la presidencia vitalicia establecida por esta Carta. Con fecha 01 de julio de 1826 el ministro Pando en circular dirigida a los prefectos remite el proyecto de Constitución propuesto para Perú.

A diferencia de lo ocurrido en la naciente Bolivia y contrariando nuestro precedente de 1823, el proceso aprobatorio de la Carta en Perú no conllevó la convocatoria a una Asamblea Constituyente, a consulta a votación general ni -como dice Belaunde-siguió la vía de afirmar la constitucionalidad preexistente para lograr dentro de ella las reformas convenientes (ya que la Constitución de 1823 estaba sólo suspendida parcialmente y no derogada), sino más bien se siguió el camino de su imposición a través de la consulta a los Colegios electorales, órganos que habían sido nominados para elegir a los representantes congresales entre otros funcionarios de la República, pero carecían de aptitudes consultivas, para participar o para definir un proceso constituyente.

Pero el pensamiento de Bolívar estaba absorbido por el temor al desorden, al caos y a la pérdida de unidad de su proyecto como para transitar por el camino del Congreso constituyente. En un testimonio directo de este parecer le manifestaba al prefecto del Cusco, General Agustín Gamarra: ${ }^{20}$

19 Víctor Andrés Belaunde informa haber accedido al borrador del mensaje que Bolívar pensaba presentar al Congreso peruano donde planteaba sólo modificar la Carta de 1823. De ello se extrae que hasta febrero de 1826 Bolívar había pensado instalar el Congreso, posición que luego cede ante la idea de acoger la carta diseñada para Bolivia. Para este cambio, considera V. A. Belaunde, influyeron los intereses del entorno del Libertador y las influencias de Páez que propone crear un vasto imperio en Sudamérica (op. cit., p. 170).

20 Carta al General Gamarra, Prefecto del Cusco de 30 de junio de 1826. Citada en Víctor Andrés Belaunde, op. cit., pp. 222 y 223. 
"El Consejo de Gobierno ha mandado reimprimir el proyecto de Constitución del Perú con la mira de comunicarlo a los Prefectos, y éstos a los colegios electorales, acompañándolo de una muy fundada exposición circulada por el Ministerio del Interior. Esta es, mi querido general, una operación que debe ejecutarse con el mayor tino y habilidad, porque su resultado es de una inmensa importancia. Es la operación que puede producir un bien perdurable para la república, y por consiguiente debe ser manejada por Ud. y el doctor Torres con perfecto acuerdo para obtener un buen resultado. Usted debe empeñarse con los colegios electorales de ese departamento a fin de que aprueben íntegramente el proyecto y en el caso de que algún artículo le ofrezca reparos puede reservarse para ser discutido o reformado en el próximo Congreso Constituyente. Obtenida la aprobación del proyecto por los colegios de la República queda sancionada la ley fundamental; nos libertamos del conflicto de un Congreso constituyente, porque ya no tiene para qué, convocarse, y los Congresos constituyentes no podrán alterar las bases esenciales de la ley fundamental ya sancionada por el pueblo en las Asambleas electorales. Eche Ud. la vista por todos los males que han producido en las nuevas repúblicas las Asambleas constituyentes, los peligros a que han expuesto a las naciones, el choque de pasiones irritadas por fuertes estímulos de odios, de intereses y de venganza, con un poder absoluto y conocerá usted con cuánta razón lo empeño en que haga pasar en los colegios electorales de ese departamento el proyecto de Constitución del Perú, que va a sometérsele para su aprobación. Estoy seguro de que si esto no se consigue, y el Perú tiene que pasar por otra terrible crisis de una Asamblea Constituyente, la República va a ser despedazada irremediablemente y destruidos para siempre los esfuerzos de tantos años».

Con razón, este procedimiento irregular, oscuro y pleno de desconfianza hacia el debate abierto fue reiteradamente considerado por sus críticos, de todo tiempo, para denostar del proyecto mismo, absorbiendo el debate y relegando a un segundo plano el contenido normativo del proyecto bolivariano.

Para acrecentar el desconcertante panorama, Bolívar partirá el 3 de setiembre de 1826 hacia Colombia -apartándose del resto del proceso de debate y aprobación de su proyecto de Constitución- dejando a don Andrés Santa Cruz a cargo del mando supremo de la República, disponiendo que la Vice-Presidencia del Consejo de Gobierno recaiga -por suerte- en alguno de sus miembros, y que el Consejo de Gobier- 
no debía convocar al Cuerpo Legislativo para setiembre de 1827 (Decreto de 01.09.1826).

\subsection{Singularidades del proyecto consultado a los Colegios electorales}

Un aspecto de corriente generalización entre los analistas de este episodio de la historia es el de la identidad de la Carta propuesta para Perú con la remitida a Bolivia.

Por ejemplo, Luis Felipe Villarán ${ }^{21}$ indica que ambos contaban con igual contenido, mientras que otros como Toribio Pacheco en sus Cuestiones Constitucionales y García Calderón en su Diccionario de Legislación peruana, expresan que el texto boliviano fue materia de modificaciones realizadas por el propio Bolívar para adecuarla a la realidad nacional. En efecto, esta última es la posición ajustada a los hechos, lo cual es ratificado por el propio texto del decreto sancionador de la Carta, cuyo tercer considerando nos indica que fue examinado y sancionado «[...] el proyecto de Constitución Política presentado por el Libertador a la República boliviana, con algunas modificaciones adoptadas a la índole y a los intereses de la nación peruana».

Un cotejo entre la Constitución Política de Bolivia dada el 19 de noviembre de 1826 y la sometida a los colegios electorales de Perú nos informa de las variantes, modificaciones y supresiones que fueron incluidas por el Libertador, para adaptar a la idiosincrasia de la sociedad peruana de la época. Las variantes apreciables fueron las siguientes:

1. Incluye a la religión Católica, apostólica y romana como religión del Perú, pero sin excluir a otros cultos como lo establecía la Carta de 1823 y era el sentir ciudadano manifestado por los colegios electorales (artículo 6\$). En este tema la propuesta muestra un retroceso en el pensamiento original liberal del Libertador, aunque mantiene la tolerancia de cultos.

2. Considera entre los nacionales peruanos a los libertadores de la República declarados como tales por la ley de 12 de febrero de 1825 , lo cual consolida una situación propia del sistema jurídico peruano que justifica la modificación (Inciso $3 \$$ del artículo $11 \$$ ).

21 Luis Felipe Villarán; La Constitución Política comentada. E. Moreno Editor. $1899 ;$ p. 25. 
3. Suprime el reconocimiento de nacionalidad y otorgamiento de libertad a los esclavos en el territorio de la patria. La propuesta para Perú no consideró el inciso 5 del artículo $11^{\circ}$ de la Carta Boliviana cuyo texto indicaba: «Todos los que hasta el día han sido esclavos; y por lo mismo quedarán de derecho libres, en el acto de publicarse la Constitución; pero no podrán abandonar la casa de sus antiguos señores, sino en la forma que la ley especial lo determine».

4. En cuanto a la ciudadanía:

a) Es elevada la edad mínima para ser ciudadano de veinte años en la Carta boliviana a veinticinco años en la Carta peruana (artículo $14^{\circ}$ inciso 2 );

b) Hace inmediatamente operativo el requisito de ser alfabeto para poder ser ciudadano, mientras que la Carta boliviana sólo hacía exigible esta condición desde 1836 (inciso 3 y artículo $24^{\circ}$ );

c) Suprime la posibilidad contemplada en Bolivia para que los extranjeros solteros con cuatro años de vecindad en la República puedan acceder a la ciudadanía (inciso 4);

d) Suprime la pérdida de la ciudadanía cuando se admite empleo, título o emolumento de otro Gobierno, sin consentimiento de la Cámara de Censores artículo $19^{\circ}$ inciso 4 , concordante con el artículo $60^{\circ}$ inciso 8 ).

5. En cuanto al Poder electoral:

a) Fueron cambiados los días previstos para la reunión del cuerpo electoral a los días 2, 3, 4, 5 y 6 de enero en vez de los días 1 al 6 de abril de la Constitución boliviana. Además, sobre las propuestas de funcionarios que debe hacer el poder electoral a otros órganos del Estado sustituye el empleo de ternas por las listas;

b) Considera a los alcaldes (en concepción distinta a los Consejos municipales) como funcionarios cuya designación ha de ser propuesta por el Cuerpo electoral al prefecto del departamento; y,

c) Suprime la facultad del Cuerpo electoral para proponer al gobierno eclesiástico una lista de curas y vicarios para las vacantes de las provincias (artículo $26^{\circ}$ inciso $4,1 \$$ ). 
6. En cuanto al Poder legislativo:
a) Eleva el número de los miembros de las Cámaras de veinte a veinticinco miembros (artículo $28^{\circ}$ );
b) Retira la exigencia de mayoría absoluta de votos del Congreso
para elegir al Presidente de la República (artículo $30^{\circ}$ inciso 1); policía interior por reglamentos y castigar a sus miembros por infracción de ellos" (Artículo $30^{\circ}$ inciso 7 );
c) Considera como atribución de cada Cámara la de «ordenar su
d) Reduce el quórum mínimo de las Cámaras a la mitad más uno, en vez de los dos tercios previstos en la norma boliviana (Art. $39^{\circ}$ inciso 1 );
e) Eleva las edades mínimas para ser Senador y Censor de treinta y treinta y cinco años, a treinticinco y cuarenta años, respectiva- mente (artículos $46^{\circ}$ y $50^{\circ}$ ).
f) Varía el procedimiento para la selección de los magistrados del Tribunal Supremo de Justicia y para arzobispos, obispos, y canó- nicos siendo iniciado por la Cámara de Senadores quien propo- ne una lista ante el Poder ejecutivo, quien la reduce a una terna y, luego, la remite a la Cámara de censores, para su decisión. Según el diseño de la Constitución boliviana en este procedi- miento no intervenía el Presidente de la República.

7. En cuanto al Poder ejecutivo:
a) Permite que los ministros de Estado presencien las votaciones del Congreso (artículo 63);
b) La Constitución peruana emplea la denominación de «Secreta-
rios de Estado" en vez de la tradicional de «Ministros de Estado»;
c) El número de Secretarios de Estado es fijado en cuatro sin iden- tificar las materias de las cuales se ocupará cada uno, mientras que la boliviana los fijaba en tres indicando su ámbito: Interior y Relaciones Exteriores, Hacienda y Guerra y Marina.

8. En cuanto al Poder judicial:
a) Elimina la mención a la exclusividad de los tribunales y juzgados para ejercer labor jurisdiccional contemplada como artículo $99^{\circ}$ de la Constitución de Bolivia;
b) Aclara que la potestad sancionadora sobre los jueces corresponde a la Cámara de Senadores y a las cortes de distrito. según rango, 
y con conocimiento del Congreso (Art. 99 $)$;

c) Limita la posibilidad de presentar denuncias por inconducta funcional de magistrados sólo al órgano del cuerpo electoral excluyendo la alternativa de la denuncia popular contemplado en Bolivia (artículo $100^{\circ}$ );

d) Excluyó tres artículos sobre la responsabilidad personal de los magistrados y jueces, al debido proceso y al derecho a la jurisdicción predeterminada (artículos $103^{\circ}, 104^{\circ}$ y $105^{\circ}$ ); sólo incluye un tímido artículo sobre la responsabilidad de los jueces de letras ante las Cortes del distrito judicial y de éstas ante el Supremo Tribunal (Art. $111^{\circ}$ ).

9. En cuanto al orden interno desdobla el ámbito de las prefecturas en sub-prefecturas y a éstas en gobernaciones, en vez de los corregidores a que alude la Constitución boliviana. Simultáneamente suprime la mención a los requisitos para ser prefecto y gobernador.

10.Incorpora el cargo del Alcalde como funcionario para los pueblos con más de dos mil habitantes, con período de mandato de dos años, precisando que pueden ser reelegidos (Art. 128 ${ }^{\circ}$ ).

11. Elimina el artículo sobre la responsabilidad de los empleados públicos por los abusos funcionales en que incurran (artículo $140^{\circ}$ en la Constitución boliviana).

12. Incluye la figura de las milicias nacionales compuestas por habitantes de cada provincia (artículo $136^{\circ}$ ).

13. Reduce el plazo para hacer la reforma obligatoria a cuatro años (artículo $138^{\circ}$ ) en vez de los diez años que prevé la constitución boliviana.

Si quisiéramos encontrar en estas variantes algunas líneas de tendencia dentro de estos cambios en el pensamiento bolivariano, podemos afirmarlas en cinco aspectos:

- Incremento del conservadurismo (mostrado en silenciar el tema de la esclavitud, la elevación de las edades para acceder a cargos y alcanzar la ciudadanía y la exigencia inmediata de ser alfabeto para ser ciudadano);

- Limitación a los canales directos de participación ciudadana (sustitución del instrumento de ternas -que limita la elección-por la de 
listas -que amplía las alternativas- en las elecciones de autoridades que debe realizar el Cuerpo electoral y limitación a presentar denuncias por inconducta judicial sólo a través del cuerpo electoral);

- Atenuación del principio de responsabilidad pública;

- Mayor presencia del Poder Ejecutivo en la designación de magistrados públicos y autoridades eclesiásticas; y,

- Atenuación de la independencia judicial, al establecer entre otros aspectos que los jueces sean designados y supervisados por el Congreso.

\subsection{La consulta a los Colegios electorales}

El análisis de las actas de las votaciones producidas en los cincuenta y nueve colegios electorales ${ }^{22}$ nos revela la intención clara de instrumentalizar la votación popular a favor del proyecto, alejándose así de la liberalidad y sumisión a la soberanía popular que se enarbolaba en los discursos.

Nos testimonian ello, el ausentismo predominante en los colegios; la premura con que se condujeron las votaciones ya que en la mayoría de los colegios sus integrantes conocieron del texto de la Carta propuesta en el mismo acto de votación, escuchando la lectura de su contenido y fueron compelidos a votación inmediata, sin permitirse mayor estudio o consulta. También llama la atención la similitud de frases que aparecen en las actas de diferentes Colegios electorales coincidentes en el sentido laudatorio a favor de la Carta que hacen dudar de su espontaneidad, a la vez que nos recuerdan al texto preparado por Antonio Leocadio Guzmán; la necesidad de reiterar convocatorias sucesivas en algunos Colegios electorales para abordar específicamente el tema de la designación del Presidente; o, la redacción premeditadamente

22 Los colegios electorales consultados fueron: Lima, Chancay, Canta, Huarochirí, Cañete, Yauyos, Santa, Ica, Huánuco, Cajatambo, Huamalíes, Pasco, Conchucos, Alto Conchucos, Jauja, Huaylas, Arequipa, Condesuyos, Caylloma, Moquegua, Arica, Camaná, Tarapacá, Bolívar (La Libertad), Jaén de Bracamoros, Lambayeque, Chota, Chachapoyas, Piura, Huamalies, Pataz, Cajamarca, Ayacucho, Andahuaylas, Cangallo, Huancavelica, Huanta, Tayacaja, Castrovirreyna, San Juan de Lucanas, Angaraez, Puno, Chucuito, Lampa, Carabaya, Azángaro, Cuzco, Paucartambo, Calca, Cotabambas, Urubamba, Chunvivilcas, Paruro, Abancay, Tinta, Quispicanchis, Parinacochas y Maynas. 
ambigua de las actas; la difusión conjunta del texto con la propaganda oficialista como fueron las publicaciones de Antonio L. Guzmán y de El Federalista; la incultura de las masas de población que son testimoniadas por ejemplo, en la posición de la parroquia de Catacaos (declararon que sometían su parecer a los señores diputados nombrados por ellos ya que no tenían capacidad para resolver las preguntas planteadas) y de Chancay (quienes declaraban que aprueban el proyecto "usando la razón más o menos clara, que es propia de todo hombre», «aunque por sus limitadas luces no pueden discernir analíticamente lo que les presenta la lectura del proyecto".

Las adiciones al proyecto constitucional planteadas por los miembros de los colegios electorales nos muestran directamente el sentir de la comunidad nacional de aquél entonces, y las podemos agrupar según su recurrencia, en:

- La intolerancia religiosa, que hizo que catorce colegios electorales manifiesten su posición a favor que la Carta consagre a la religión católica, apostólica y romana como la única de la República excluyendo cualquier otra confesión, llegando incluso, en este orden de ideas, a proponer los representantes de Chota que «sólo los católicos pudieran alcanzar empleo civil o políticon, los que Cotabambas que se excluya de modo absoluto «el ejercicio público o privado de cualquier otra" y los de Chalhuanca a favor que la religión oficial sea "para siempre la cristiana santa católica, apostólica y romana, sin que sea admisible el ejercicio de ninguna otra que directa o indirectamente se oponga a ella en lo más leve y que sea castigado quien por sí o por otro intente la introducción de otra secta».

- Una tímida desconfianza sobre la permanencia del régimen de sucesión con posterioridad a Bolívar, patentizado en los pareceres de algunos colegios electorales, como los de Cañete en el sentido que el Libertador sea nombrado por el Colegio Electoral; de Huánuco (quien no obstante aprobar, en segunda convocatoria, la designación de Bolívar dejó constancia que entendían que tal designación debía realizarla el Congreso), de Cajatambo para quien la elección de Bolívar requería la previa derogación del extremo del artículo $79^{\circ}$ de la propia Carta que consideraba como requisito para acceder a la Presidencia la nacionalidad originaria peruana; de Pasco en el sentido que el sucesor de Bolívar no sea vitalicio y tenga responsabili- 
dad; del colegio de Bolívar que pedía que se consigne que el Vicepresidente no podría ser familiar del presidente; y de Cajamarca que planteaba que el sucesor de Bolívar debía tener período fijo con opción a reelección, sujeto a responsabilidad por los actos de su administración.

- La desconfianza sobre el régimen de reelección para autoridades locales (Colegios electorales de Cañete, Pazco y Jauja).

Adicionalmente a estas recurrentes posiciones fueron argumentados otros planteamientos a favor de reducir la exigencia de tres años para obtener nacionalidad peruana, con la finalidad de estimular el ingreso de extranjeros (Colegio de Bolívar); de mantener la previsión para que hasta el año cuarenta puedan ser ciudadanos quienes no sabían leer ni escribir (Colegio de Cañete) y la posición del colegio de Arequipa quien indicó que fuese efectivo el sistema federal con los demás Estados.

La única posición adversa a la aprobación del proyecto de Carta fue la abstención del colegio de Tarapacá ${ }^{23}$, quien consideró que para esta aprobación se necesitaba la reunión del cuerpo legislativo, pero se sometía a la opinión de Arequipa y expresaba su obediencia al gobierno siempre que, como esperaba, la Carta estuviere conforme con los principios liberales adoptados por el Perú y continente americano. Afirmó que:

«[...] no teniendo luces suficientes para el desempeño de función tan augusta como delicada de sancionar un proyecto de Constitución de que depende la felicidad de la República, tan amantes de ello como el que más, porque le deben su ser y subsistencia pasan por el pudor de hacer esta ingenua confesión en la que sin desdeñar un punto del proyecto que suponen la promueve la obra del genio que preside hoy la República, como que le ha dado su libertad, tampoco la sancionan por no creerse con las aptitudes necesarias para un acto que no sin los más graves fundamentos se resigna comúnmente al cuerpo legislativo, que por lo regular lo componen los hombres de probidad suma y luces tan esclarecedoras que los elevan entre millares al rango de legisladores, que conocer los exponentes que no pueden ocupar sin traicionar a sus sentimientos de ingenuidad que en semejante caso debe presidirlos.

23 Pareja Paz-Soldán noticia que el planeamiento de Tarapacá se debía a la posición nacionalista de Ramón Castilla. 
Que por conclusión aseguran al Excmo. Consejo de Gobierno que jamás su ciega obediencia desmentirá un punto los deberes que les ligan a S. E. y autoridad suprema que le sucede como ni tampoco su adhesión a las decisiones que con mejor acuerdo y luces se emitan en la capital del departamento a que está sujeta esta provincia, a la sombra de su esclarecido jefe, siempre que como esperan, guarde consonancia y analogía con los principios liberales adoptados por unánime sentir y aclamación del Perú y continente americano, que para lograrlos, no ha omitido sacrificio de ninguna clase a despecho del gobierno antiguo español y con aprobación de cuantos pretenden tiranizar los pueblos y hollar los sagrados derechos del hombre [...]».

\subsection{Aprobación del proyecto. Crítica al proceso}

El incierto proceso de aprobación del proyecto manifiesta sus apresuramientos y desvios por acontecimientos, tales como: la oposición entre el Consejo de Gobierno y los diputados reunidos en Lima que pretendían la instalación del Congreso, las diferencias públicas entre el Consejo de Gobierno y Bolívar con el líder visible de la oposición, Luna Pizarro a quien negó audiencia repetidas veces ${ }^{24}$, la amenaza de Bolívar

24 La posición opositora de Luna Pizarro no era absolutamente radical pues coincidía en la obvia necesidad de reformar la Carta de 1823 y no era totalmente adverso a la continuidad de Bolívar nos informa Víctor Andrés Belaunde basado en testimonios de la época del cónsul americano Mr. Tudor. Curiosamente la percepción de Simón Bolívar sobre Luna Pizarro no fue precisamente uniforme ya que por ejemplo en su carta de 27 de octubre de 1825 dirigida al General Tomás de Heres referente a los cambios que deben realizarse dentro de la administración peruana le indica; "Yo desearía que el señor Unanue fuese nombrado vicepresidente; que el señor Larrea fuese al istmo en lugar del señor Pando; y el señor Luna Pizarro fuese nombrado secretario de gobierno [...] pues el ministerio de gobierno requiere un hombre como Luna Pizarro, de talento, crédito y energía, amigo de La Mar y enemigo de Torre Tagle»; sin embargo, el 7 de abril de 1826 en la carta dirigida al general Santander con motivo de los enfrentamientos con los diputados que deseaban reinstalar el Congreso le diría: "[...] El motivo principal de todo esto es que un tal Luna Pizarro, un cleriguito como el doctor Pérez, ha querido que la constitución varíe, o más bien que él pueda disponer de todo a su antojo. El fue el que echó de aquí a San Martín y el que perdió a la junta que presidía La Mar; y él es el que ha pedido a Arequipa sus poderes sin restricción alguna, y como no pueden entrar en el congreso con estos poderes, los de Arequipa han querido sostener su partido». (Jorge Pérez Concha; Pensamiento Político de Bolívar, pp. 73 y 87). 
de retirarse del Perú; y por las idas y venidas para la verificación oficial de las actas de los colegios.

Primero se pretendería someter a la Corte Suprema la verificación de las cincuenta y nueve actas de los Colegios Electorales, pero luego el Ministro Pando remitiría lo actuado al Cabildo de Lima (28.11.1826) para que examine «las actas, confronte el ejemplar impreso que se envía con el proyecto de Constitución, manifestar su conformidad o no y exponer cuales son los votos de los Colegios" sobre los temas sometidos a su opinión. No obstante carecer de competencia alguna para pronunciarse en este tema, el Cabildo manifestó "haber examinado las actas originales de los Colegios Electorales, hallándolas conformes con las impresas a continuación de la Constitución y reconocido que la calidad de ellos ha sancionado el proyecto de Constitución, sometido a su juicio [...]», conforme consta en los vistos del Decreto aprobatorio de la Carta.

Mucha razón tiene Fraga Iribarne cuando afirma que «más que el texto mismo, la velocidad y los procedimientos que se utilizaron para implantarlo, dañaron a la nueva Constitución $\aleph^{25}$, ya que trató de un cauce deliberadamente imprevisible desde su inicio, donde, por ejemplo, no hubo claridad y uniformidad en los procedimientos seguidos ante los Colegios electorales, no se previno acerca de la atención que debía darse a las discrepancias mostradas por los colegios, las que finalmente fueron desestimadas sin contemplar siquiera algún análisis o pronunciamiento, la premura pública por obtener su consagración contribuyó a que se incrementara la sensación de una imposición, etc.; apoyando la tesis que para este entonces, el Libertador había sido ganado por ideas absolutistas y desconfiadas acerca de la participación política.

Finalmente, fue declarada como Ley fundamental del Perú el 30 de noviembre mediante decreto del Consejo de Gobierno suscrito por don Andrés Santa Cruz (Presidente), José de Larrea y Loredo (Vocal), Tomás de Heres (Vocal) y José María Pando (Vocal). Luego, fue juramentada el 09 de diciembre de 1826 -como homenaje al segundo aniversario de la Campaña de Ayacucho- por las autoridades principales del Estado y en sesiones sucesivas por las autoridades locales, subalternas, vecinos y fuerzas armadas. 
Desde su mismo inicio, la Constitución vitalicia ocasionó resistencia en diversos sectores de la sociedad peruana, la cual alcanzó su máxima expresión con el motín del 26 de enero de 1827, jefaturada militarmente por el comandante José Bustamante quien apresó y deportó a los jefes militares leales a Bolívar. Ello, obligó al Consejo de Gobierno presidido por Santa Cruz a convocar al día siguiente a elecciones para un Congreso Constituyente extraordinario que con arreglo a la Constitución de 1823 decidiera sobre la Carta que debía regir y sus autoridades.

Finalmente, el Congreso General Constituyente presidido por Javier de Luna Pizarro decretó la Ley de 11 de junio de 1827 declarando la nulidad de la Constitución vitalicia afirmando que fue sancionada de modo ilegal y atentatorio a la soberanía nacional por faltar al pacto social.

De tal modo, el tiempo de preparación de la Carta fue más amplio que las escasas semanas durante las cuales alcanzó formal vigencia en territorio peruano.

\section{Análisis del proyecto constitucional bolivariano}

\subsection{Influencias notables en el contenido del proyecto}

Premunido de un fuerte intelecto, hábil para el análisis y con amplia cultura política sobre la ideología de su tiempo, Bolívar prepara su proyecto de Constitución haciendo interactuar diversos pensamientos, ideologías, textos constitucionales conocidos, tratando de buscar lo que consideraba el justo medio entre estabilidad y liberalismo.

Es injusto Toribio Pacheco cuando afirma que el texto constitucional es un plagio de la Constitución consular de Napoleón. Fue una de sus fuentes, pero reconoce otras recepciones, amén del aporte personal indudable que significó la continuidad del pensamiento bolivariano proveniente desde Angostura (entre los cuales debemos anotar la pedagogía democrática y moral, ética y responsabilidad gubernativa, presidencialismo, realismo o pragmatismo jurídico, paternalismo, desconfianza frente al autogobierno y su perfeccionismo). Como afirma Fraga, "[...] no se aferró a ningún modelo ni sirvió a ningún dogma», «no se aferró a ningún dogma y mantuvo vivo y creador su pensamien- 
to para hacer frente a las nuevas situaciones y problemas, adaptándolo constantemente a nuevas emergencias".

En el origen mismo del pensamiento constituyente de Bolívar se encuentra una fuerte dosis de desconfianza frente a la posibilidad del autogobierno de las ex-colonias españolas por la escasa experiencia y capacidad para desempeñar eficientemente tareas de gobierno. Tal es esta actitud que en su célebre "Contestación de un americano meridional a un caballero de esta isla» (Kingston, 6 de setiembre de 1815) llegaba a afirmar:

«[...] Los americanos, en el sistema español que está en vigor, y quizá con mayor fuerza que nunca, no ocupan otro lugar en la sociedad que el de siervos propios para el trabajo, y cuando más, el de simples consumidores; y aun esta parte coartada con restricciones chocantes [...]. Estábamos como acabo de exponer, abstraídos, y digámoslo así, ausentes del universo en cuanto es relativo a la ciencia del gobierno y administración del Estado. Jamás éramos virreyes ni gobernadores, sino por causas muy extraordinarias; arzobispos y obispos pocas veces; diplomáticos nunca; militares, sólo en calidad de subalternos; nobles, sin privilegios reales; no éramos, en fin, ni magistrados ni financistas, y casi ni aún comerciantes, todo en contravención directa de nuestras instituciones $[\ldots]$.

Los americanos han subido de repente y sin los conocimientos previos, y, lo que es más sensible, sin la práctica de los negocios públicos, a representar en la escena del mundo las eminentes dignidades de legisladores, magistrados, administradores del erario, diplomáticos, generales, y cuantas autoridades supremas y subalternas forman la jerarquía de un Estado organizado con regularidad".

Esta desconfianza -fruto del realismo de su análisis político- conllevó a que del mismo modo juzgue, como inadecuada en aquella época inicial la instalación de las instituciones "perfectamente representativas" o de un esquema liberal no obstante su conocida admiración por la organización política británica. ${ }^{26}$

26 En esta misma carta se plantea el Libertador la siguiente pregunta; ¿seremos nosotros capaces de mantener en su verdadero equilibrio la difícil carga de una república? ¿Se puede concebir que un pueblo recientemente desencadenado se lance a la esfera de la libertad, sin que, como a Icaro, se le deshagan las alas y recaiga en el abismo?. (Hernández Sánchez-Barba, M.; op. cit., p. 163 y ss). 
Desde antes, Bolívar no ocultaba ${ }^{27}$ su cercanía con el modelo inglés al cual califica como la «monarquía bien regulada», que ha llevado a Inglaterra a ser la envidia de todos los países del mundo confesando que es el modelo que «todos desearíamos en nuestras constituciones y gobiernos». Incluso su edecán O’Leary nos narra que «Los ratos que Bolívar podía sustraer a sus urgentes ocupaciones las dedicaba diligentemente y con asidua aplicación al estudio de la Constitución británica y fue tanta su admiración por las instituciones inglesas, que formó la resolución, si alguna vez llegaba a tener influencia suficiente en su patria, de trasplantar a ella esas instituciones, hasta donde los permitieran las diferencias [...]” (citado por Bákula, p. 17).

Precisamente, Bolívar durante esta época se enorgullece que su texto fundamental represente la combinación y asimilación de diversos pareceres, afirmado que la inconveniencia de formas puras de gobierno, sea el federal (como reconocía a las instituciones representativas) o el monárquico, ya que ambos exigen virtudes y talentos políticos muy superiores a aquellos presentes en la realidad americana de la época. Por ello, proclama en 1815 la necesidad de buscar un medio entre ambos extremos que evite caer en «anarquías demagógicas» o en «tiranías monócratas».

Esta línea de pensamiento en favor de las fórmulas mixtas de gobierno, la continúa cuando genera el proyecto constitucional para Bolivia. Al General Páez le informa que «esta Constitución es un término medio entre el federalismo y la monarquía" (Carta de 26 mayo de 1826); mientras que al General Santander le dice «mi proyecto concilia los extremos: los federalistas encontrarán allí sus deseos realizados en gran parte y los aristócratas hallarán un Gobierno permanentemente, sólido y fuerte; los demócratas verán conservada la igualdad sobre toda cosa" (Carta de 30 mayo de 1826). A Tomás Cipriano de Mosquera le indicaba: «En él están reunidos todos los encantos de la federación, toda la solidez del Gobierno Central, toda la estabilidad de los Gobiernos monárquicos" (Carta de 8 de agosto de 1826); por su parte, cuando se dirige a Buchet de Martigny le refiere «Tal vez habrá usted visto mi proyecto de Constitución para Bolivia, donde introduje

27 Carta citada por María Cecilia Bákula Budge. Los ideales de Bolívar en la integración de los pueblos hispanoamericanos. Publicaciones de la Comisión Nacional del Sesquicentenario de la Independencia del Perú. Lima-Perú, 1975, p. 18. 
los mejores principios del gobierno monárquico y al juntarlos a los más democráticos, trató de evitar los abusos de éstos». Y finalmente en su comunicación a los departamentos del norte les decía «En ningún pacto de los Gobiernos representativos veo tanta libertad popular tanta intervención inmediata de los ciudadanos en el ejercicio de la soberanía y tanta fuerza en el Ejecutivo como en este proyecto. En él están reunidos todos los encantos de la federación, toda la solidez del Gobierno Central, toda la estabilidad de los Gobiernos monárquicos. Están enlazados todos los intereses y establecidas todas las garantías».

Por otro lado, los estudiosos mencionan como textos legales influyentes en esta propuesta: la Constitución de Haití de 1816 y Venecia (Pombo y Guerra), de EE. UU. y en particular de Virginia, la Constitución Española de las Cortes de Cádiz de 1812, la Constitución francesa del Imperio napoleónico y el proyecto de Sieyes (Otero), entre otras. Sin embargo, consideramos que difícilmente pueda admitirse que el proyecto acoja ideas de todos estos ordenamientos, mas bien, entre ellas existen líneas de tendencias y fuentes troncales con las cuales se emparentó el pensamiento bolivariano.

\subsubsection{El pensamiento filosófico-político de Jeremy Bentham}

Hacia 1819, en su célebre discurso de Angostura, Bolívar afirmaba:

«El sistema de gobierno más perfecto es aquel que produce mayor suma de felicidad posible, mayor suma de seguridad social y mayor suma de estabilidad política.»

patentizando un innegable parentesco con el principio de la mayor felicidad del mayor número planteada por Jeremy Bentham durante la misma época en Inglaterra. Resaltar esta característica resulta importante en el estudio del pensamiento político, en general, y constituyente, en especial, de Bolívar, por cuanto nos revela una influencia que no es remota o simplemente la que pudiera derivarse de un interesado lector de las ideas filosóficas contemporáneas de su tiempo, sino por el contrario de un ascendiente directo en el desarrollo del pensamiento bolivariano durante la segunda década del siglo pasado. 
En efecto, existe evidencia no suficientemente publicitada ${ }^{28}$ pero corroborada por ambas fuentes acerca de la vinculación personal entre ambos personajes relacionada con la Constitución bolivariana y los primeros proyectos del Constitutional Code elaborado por Bentham. Para esto debemos recordar que Jeremy Bentham fue un inusual filósofo que dedicó esfuerzos a difundir su particular perspectiva de la legislación (asesor de técnica y contenidos normativos) así como un asiduo proyectista de textos legales para nuevos Estados, que en lo atinente a la materia constitucional mostró su auge precisamente hacia las primeras décadas del siglo pasado. Muchos aportes de este filósofo fueron ofrecidos, llegando a integrar secciones, cuando no textos enteros, de Constituciones vigentes en diversos Estados. De ello, nos dan cuenta Francia (lo cual le deparó ser declarado ciudadano francés honorario aunque luego su texto fuera rechazado), Grecia, Rusia, Liberia, Portugal y en nuestra América su contacto directo con Pedro El Grande (Brasil), Bernardino Rivadavia (Argentina), José del Valle (Centroamérica), Petion (Haití) y Miranda (precursor de la independencia americana).

En su documentado ensayo sobre John Dinwiddy Bentham, ${ }^{29}$ afirma que en su afán de difundir su Constitutional Code de esencia utilitarista, Bentham sostuvo correspondencia con Simón Bolívar, informándonos sobre éste último, que "en una larga carta a Bolívar en agosto de 1825. Bentham afirmaba que de entre todos los estados del mundo, Colombia le parecía a él aquel en que la ilustración de la elite gobernante era más probable que hiciese aceptable su Constitutional Code $[\ldots]$.

Por su parte, en su no suficientemente mencionada investigación de Gustavo Adolfo Otero sobre la documentación de Bolívar ${ }^{30}$, confirma esta conexión afirmando:

28 De una revisión efectuada a los principales estudios históricos constitucionales nacionales que abordan la Constitución de 1826 sólo encontramos la mención a esta influencia en el estudio de Francisco García Calderón.

29 John Dinwiddy.- Bentham, p. 30. Alianza Editorial. El Libro de Bolsillo Nº 1764, Sección: Humanidades.

30 "Bolívar y Bentham (Génesis de la Constitución Boliviana de 1826)". En: Historia Revista de Cultura $N^{\circ}$ 6, Volumen segundo. Enero-junio de 1944. Lima (Perú). 
"[...] Ahora en 1825, Bolívar era para Bentham una tentación y una meta. El fabricante de constituciones, entabla una correspondencia con Bolívar y le remite un proyecto de Código constitucional precisamente cuando el Libertador recibía la solicitud del Congreso de Chuquisaca, para que le diera un estatuto constitucional. Por lo que tenemos averiguado fue Bentham el que se acercó al Libertador, abriendo el filósofo el camino para una correspondencia en igual forma como había hecho con otros personajes de nuestra América.

Esta correspondencia entre Bolívar y Bentham hasta el presente permanece inédita y sólo se conocen de ella algunas piezas lo suficientemente elocuentes y precisas, para que sin recurrir a lo oculto, podamos formarnos una idea de las relaciones que existieron entre el Libertador y el jurisconsulto británicom. ${ }^{31}$

¿Pero qué, aspectos de la Constitución de Bolivia muestran la influencia del pensamiento utilitarista? Definitivamente, careciendo de la correspondencia epistolar entre ambos personajes que nos informe de modo directo sobre los aportes específicos suministrados al Libertador, sólo podemos - por vía deductiva- afirmar algunos puntos de contacto entre las propuestas utilitaristas y el texto consagrado, tales como los siguientes: la inviolabilidad del domicilio y de la correspondencia, la responsabilidad de los funcionarios, el orden en los juicios, la proscripción del tormento, la independencia del poder judicial y la consagración entre los deberes ciudadanos el sacrificio de sus intereses en función del interés de la mayoría.

\subsubsection{La influencia del «poder neutro» de Benjamin Constant}

En su detenido estudio sobre los aportes del pensamiento político de Benjamin Constant en el diseño constitucional del Libertador, Hermann Petzold-Pernia ${ }^{32}$ encuentra puntos de contacto alrededor del tratamiento

31 Otero transcribe una carta de Bentham, fechada el 13 de agosto de 1825 dirigida a Bolívar en la cual le indica: «Me gustaría que la correspondencia que tengamos quede oculta entre las sombras antes que su publicación despierte en alguna parte celos que tiendan a perjudicar los fines que se procuran". (op. cit., p. 81), lo cual explicaría que hasta la fecha no se haya conocido el contenido de tan importante comunicación epistolar para desentrañar objetivamente la influencia de la filosofía utilitaria en el pensamiento constituyente bolivariano.

32 Hermann Petzold-Pernia; «La influencia de Benjamín Constant en el Libertador Simón Bolívar». En: Estudios de Derecho, Volumen XLII, Nº 103; p. 37 y ss. 
dado al poder ejecutivo y al poder neutro, a la concepción de soberanía limitada, la revalorización del poder judicial, el empleo de los jurados, así como en materia de libertad religiosa. Si bien en estos temas existen planteamientos coincidentes, no necesariamente son originados en una exclusiva incidencia de uno con el otro, sino en compartir la ideología preponderante sobre temas comunes como son la revalorización del poder judicial y el tratamiento a la libertad religiosa. Donde definitivamente sí hay vinculación directa es en el aspecto del poder neutro y en la concepción de soberanía limitada.

Las simpatías que el modelo de organización constitucional británico despertó en Constant y en Bolívar, originó que reposen su atención en la importancia, efectos y singularidad de la figura del rey. Para Constant éste era la encarnación del poder neutro o moderador que hacía preeminente a la monarquía constitucional sobre las demás formas de gobierno: aquel poder que identificó como la fuerza que al margen de los poderes ya establecidos corregía sus desvíos y reparaba los entrampamientos, sin llegar a absorber la totalidad del poder, con el objetivo de conservar el orden y la libertad regular. ${ }^{33}$

En su célebre Discurso de Angostura el Libertador declárase seguidor del poder neutro, y agregaba la idea que no debía tener su origen en la fuente electoral dejando espacio para la vitalicidad del mandatario, diciendo lo siguiente:

33 «La monarquía constitucional nos ofrece, como ya se ha dicho, este poder neutro tan indispensable a toda libertad regular. El rey, en un país libre, es un ser aparte, por encima de la diversidad de opiniones, no teniendo otro interés que el mantenimiento del orden y el mantenimiento de la libertad, no pudiendo entrar jamás en la condición común, inaccesible, por tanto, a todas las pasiones que esta condición hace nacer y a todas aquellas que la perspectiva de volverse a hallar en ella sustenta necesariamente en el corazón de los agentes investidos de un poder momentáneo. Este augusto poderío de la realeza debe esparcir en el espíritu de un monarca la calma y en su alma un sentimiento de reposo, que no puede ser patrimonio de individuo alguno en una posición inferior. Se eleva, por decirlo así, encima de las agitaciones humanas y es la obra macstra de la organización política haber sido creado en el seno mismo de los disentimientos, sin los cuales ninguna libertad existe, una esfera inviolable de seguridad, de majestad, de imparcialidad, que permite a estos disentimientos desarrollarse sin peligro, en tanto que no excedan ciertos límites y que en cuanto el peligro se anuncia, le pone término por vías legales constitucionales y desligados de toda arbitrariedad [...]" Benjamín Constant; "Curso de Política Constitucional». Ediciones Taurus, Serie Clásicos de la Política Nº3.1968, p. 16 y ss. 
"[...] Por tanto, es preciso que en todos los gobiernos exista un cuerpo neutro que se ponga siempre de parte del ofendido y desarme al ofensor. Este cuerpo neutro para que pueda ser tal, no ha de deber su origen a la elección del gobierno, ni a la del pueblo, de modo que goce de una plenitud de independencia que ni tema, ni espere nada de estas dos fuentes de autoridadn. ${ }^{34}$

Estas ideas se proyectan propiamente en el diseño de Angostura a través de la Cámara de Senadores y en su posterior planteamiento para Bolivia de la Presidencia vitalicia separada del Vicepresidente que aparece como el verdadero encargado de los asuntos administrativos. En efecto, esta relación también la percibió la Comisión de Negocios Constitucionales de Bolivia encargada de revisar el proyecto, cuando afirmaba en su informe al pleno del Congreso:

"[...] El Presidente vitalicio es aquel poder neutro o intermediario, tan aplaudido por los escritores modernos para mantener el equilibrio de los otros, y aquel ser separado del ejecutivo, superior a la diversidad de opiniones y colocado innoblemente sobre la atmósfera de las disensiones e intereses. La perpetuidad agotando los deseos del jefe supremo del estado debe producir en su corazón una calma que será el apoyo de la paz y felicidad pública».

Lo que parece conscientemente no haber atendido Bolívar -fiel lector de Constant- es su advertencia en líneas siguientes cuando indica: «[...] Pero se pierde esa inmensa ventaja, ya rebajando el poder del monarca al nivel del poder ejecutivo, ya elevando el poder ejecutivo al nivel del monarca. Si confundís estos poderes, dos grandes cuestiones se hacen insolubles: una, la disolución del poder ejecutivo propiamente dicho; otra, la responsabilidad".

\subsubsection{El constitucionalismo francés: Napoleón}

Mucho se ha mencionado sobre la pretendida simetría entre la Constitución de 1826 y la de Napoleón preparada para Francia, particularmente con la acusación de plagio que hace Toribio Pacheco en sus Cuestiones Constitucionales. 
Sin embargo, la apreciación más exacta pertenece a Fraga Iribarne, para quien:

«Es evidente que la Constitución del 22 de Frimario del año VIII (13 de diciembre de 1799) con su primer cónsul; la de 16 de Thermidor del año X (4 de agosto de 1802) con su Cónsul vitalicio; ciertas fórmulas de las mismas, como el Senado, el Consejo de Estado, los Colegios Electorales, estuvieron en el ánimo de Bolívar, llamado a resolver problemas en cierto modo análogos, de establecer el orden después de la Revolución y una República capaz de funcionar. Pero sus soluciones son diferentes en el fondo y en la forma, y pensadas expresamente para el mundo americano. Recuérdese que cuando la estrella de Bolívar está en lo alto, Napoleón está olvidado; muerto en Santa Elena en $1821 \% .35$

Particularmente apreciaremos esta conexión en aspectos orgánicos de la estructura de los poderes como son el Consulado y la Presidencia vitalicios, la nominación de los Cónsules y del Vicepresidente, la estructura tricameral de la Constitución y en las potestades electorales de segundo nivel.

\subsubsection{La Constitución de Haití de 1816}

La única realidad constitucional que expresamente el Libertador alude durante esta época como fuente directa de su proyecto es la Constitución de Haití de 1816 establecida por Petion. Tanto en su correspondencia como en el propio Discurso presentado al Congreso boliviano hace mención concreta de este régimen político, calificándole como el régimen más democrático del mundo, particularmente porque luego de una sucesiva inestabilidad, la propuesta de un Presidente vitalicio con derecho a elegir al sucesor había dotado la calma al Estado e incluso permitido el tránsito en el mandato.

Sin embargo, debemos de mencionar que en este extremo la Constitución de Haití no poseía la autenticidad que parece atribuirle Bolívar, siendo mas bien una recepción de la Constitución francesa de 1789. La intención de no atraer sobre esta última, puede haber sido el motivo 
por el cual Bolívar haya señalado como arquetipo a emular a tan modesta e internacionalmente intrascendente Carta.

\subsection{Análisis del contenido de la propuesta bolivariana para Perú}

\subsubsection{Abolición de la esclavitud}

Uno de los aspectos que se resalta linealmente en el pensamiento bolivariano es su claro planteamiento a favor de la libertad civil y la igualdad mediante la abolición total de la esclavitud, considerada por el Libertador como una locura. En este tema ya Bolívar había avanzado mediante sus acciones personales (personalmente manumitió a sus propios esclavos), lo mantuvo permanentemente en sus proclamas personales, y en sus proyectos constitucionales para Angostura y Bolivia. Y, por ello, su proyecto para este último país, preveía como bolivianos:

«Todos los que hasta el día han sido esclavos; y por lo mismo quedarán de derecho libres, en el acto de publicarse la Constitución; pero no podrán abandonar la casa de sus antiguos señores, sino en la forma que la ley especial lo determine» (artículo $11^{\circ}$ inciso 5).

Contribuyeron a que esta disposición fuese incorporada en Bolivia sin mayores resistencias tanto la gran autoridad moral del Libertador proveniente del hecho de haber sido su creador, como la inexistencia de una clase social que por su propia existencia y poder pudiera oponerse a la medida. Precisamente la presencia de fuertes intereses de clase predominantes en la sociedad peruana de la época, hicieron que el Libertador repensase esta definición, que no la incorpore al texto consultado en Perú, y finalmente que se frustrase la incorporación de este avance en la historia del Perú. Fueron esos mismos intereses los que se opusieron y finalmente hicieron que fueran letra muerta los decretos de San Martín de 1821 aboliendo el tributo de los indios y condenando todas las formas de servidumbre personal; así como postergaron hasta la revolución liberal de 1854 la abolición de la esclavitud en nuestro país. 


\subsubsection{Los derechos y deberes ciudadanos en la propuesta}

Simón Bolívar prometió, a partir de Bolivia, otorgarle la Constitución más liberal del mundo, como compromiso que la Carta contendría disposiciones a tono con los derechos naturales de la sociedad. Por ello, siguiendo la tendencia francesa establecida en el Acto Constitucional del 24 de junio de 1793, su texto proclamaba cuatro derechos civiles del hombre y ciudadano: la igualdad, la seguridad personal, la propiedad y la libertad civil; además de consagrar derechos políticos, tales como: libertad de prensa y libertad de expresión sin censura previa, derecho a presentar peticiones indirectas a través de las autoridades de los colegios electores (constituyendo una regresión del derecho de petición directo que establecía la Carta de 1823), derecho a la participación en los cargos públicos mediante el poder electoral, entre otras.

La igualdad entre los componentes de la sociedad estaba, a la vez que declaraba como tal, ejemplificada mediante disposiciones concretas, como las siguientes:

a) La extinción de los empleos y privilegios hereditarios (considerado también en la Carta de 1823) e,

b) Igualdad de cargas tributarias, tendiendo a la proporcionalidad (considerado también en la Carta de 1823).

La seguridad personal entendida como el conjunto de condiciones jurídicas orientadas a evitar las agresiones ilegítimas a las personas componentes de la nación, fue considerada con tal importancia que dejaron sentadas las bases constitucionales para el establecimiento posterior del hábeas corpus. Eran condiciones para la seguridad personal consagrados en la Carta:

a) La inviolabilidad de la casa doméstica considerándola un asilo donde sólo podía ingresar de día y con orden judicial y de noche únicamente con el consentimiento del titular;

b) Inviolabilidad de la correspondencia;

c) Restricciones al poder ejecutivo a favor de la seguridad individual;

d) Judicialidad de las ordenes de detención;

e) Deber de comunicar el motivo de las detenciones;

f) Juicio por jurados; 
g) Extinción de penas crueles, el tormento, la infamia trascendental y proscribe la confesión en causa propia.

En cuanto a la seguridad propone una contribución que lamentablemente no tuvo la trascendencia debida en las Constituciones sucesivas por la resistencia que generó la integridad del proyecto bolivariano. Propuso como norma fundamental el principio que la detención de los ciudadanos sólo podía suscitarse por decisión judicial -no de los órganos administrativos-, previo proceso abierto, información oportuna del motivo de la detención, presentación ante el juez dentro de las cuarenta y ocho, y contemplando la posibilidad de interponer una acción popular en caso las autoridades administrativas se extralimiten afectando la libertad.

El articulado respectivo establecida:

"Artículo $117^{\circ}$.- Ningún peruano puede ser preso sin precedente información del hecho por el que merezca pena corporal y un mandamiento escrito del Juez ante quien ha de ser presentado, excepto en los casos de los artículos $84^{\circ}$, restricción segunda, $123^{\circ}$ y $133^{\circ} .{ }^{36}$

Artículo $118^{\circ}$.- Acto continuo, si fuere posible, deberá dar su declaración sin juramento, no difiriéndose, ésta en ningún caso por más tiempo que el de cuarenta y ocho horas».

36 Los artículos aludidos establecían como excepciones a este principio de resguardo a la libertad ciudadana:

Artículo $84^{\circ}$.- Son restricciones del Presidente de la República:

2.- Cuando la seguridad de la república exija el arresto de uno o más ciudadanos, no podrá pasar de cuarenta y ocho horas sin poner al acusado a disposición del tribunal o juez competente.

Artículo $123^{\circ}$.- Si en circunstancias extraordinarias la seguridad de la República exigiere la suspensión de algunas de las formalidades prescritas en este capítulo, podrán las Cámaras decretarlo. Y si estas no se hallasen reunidas podrá el Ejecutivo desempeñar esta misma función como medida provisional y dar cuenta de todo en la próxima apertura de las Cámaras, quedando responsable de los abusos que haya cometido. Artículo $133^{\circ}$.- Les está prohibido todo conocimiento judicial (a los Prefectos, subprefectos y gobernadores): pero si la tranquilidad pública exigiese la aprehensión de algún individuo y las circunstancias no permitiesen ponerlo en noticia del Juez respectivo, podrán ordenarla, desde luego dando cuenta al Juzgado que compete dentro de cuarenta y ocho horas. Cualquier exceso que cometan estos Magistrados relativo a la seguridad individual o a la del domicilio, produce acción popular. 
De este modo, el texto constitucional bolivariano tendía los cimientos para que el Perú desarrolle legislativamente la figura del hábeas corpus desde los inicios de su existencia resguardando así la libertad y seguridad ciudadana. ${ }^{37}$

Por su parte, el derecho a la propiedad era protegido por:

a) La extinción de las vinculaciones;

b) La libertad de trabajo;

c) La libertad de tránsito;

d) La propiedad de los inventos;

e) Libre comercio de la propiedad religiosa;

f) Abolición de las confiscaciones; y,

g) La expropiación es decidida en vía administrativa pero sólo por interés público, urgencia y previa indemnización al propietario.

Tales consagraciones para Bolivia, como nación recién independiente, resultaba de avanzada; sin embargo, para la nación peruana, cuya proclamación de derechos provenía de la Carta 1823, la conclusión no es precisamente la misma por todo lo mayormente que ya preexistían en nuestro ordenamiento, salvo en lo referente a la seguridad personal donde sí existen verdaderas innovaciones sin precedente que no fueron acogidas en lo inmediato.

Reflejando el pensamiento perfeccionista del Libertador en su búsqueda de equilibrio, los derechos son aparejados de los deberes que son impuestos a cada peruano a favor de la República y de la sociedad (Art. $\left.12^{\circ}\right)$. Entre ellos tenemos:

a) Vivir sometido a la Constitución y a las leyes;

b) Respetar y obedecer a las autoridades constituidas;

c) Contribuir a los gastos públicos;

$37 \mathrm{El}$ propio Antonio Guzmán, exegeta del texto constitucional en 1826, al comentar este articulado reconocía la incorporación del Hábeas corpus expresando: «[...] La Constitución será un ejide con que cada Ciudadano cubra su cuerpo; y el legislador ha creído que debe defenderlo con el código fundamental. El Hábeas corpus de estos hombres está escrito sobre su pacto" (op. cit., p. 18). 
d) Sacrificar sus bienes y su vida misma cuando lo exija la salud de la República, incorporando así un principio singular de neto corte utilitarista a favor de la felicidad de la mayoría; y

e) Velar sobre la conservación de las libertades públicas.

3.2.3 Las secciones en que se divide el poder público: poder legislativo tricameral, poder ejecutivo complejo, poder judicial independiente y poder electoral

Un primer aspecto a considerar en el planteamiento constitucional de Bolívar es su propia visión acerca de la existencia de un poder público supremo que para su ejercicio se divide en secciones (electoral, legislativa, ejecutiva y judicial) y no se tratan de tres poderes esencialmente diferentes que han de relacionarse dentro de un Estado. Es un distingo conceptual esencial que otras Cartas nacionales han omitido establecer positivamente.

Luego de sostener la unidad esencial del poder público, el Libertador consagra la limitación absoluta a fin que cada sección ejerza sus tareas sólo dentro de lo facultado por la Carta, delimitando sus tareas e impidiendo la posibilidad de asumir atribuciones implícitas o interpretaciones extensivas que afecten la soberanía popular y más aún sujeta a cada órgano del poder público a restricciones expresas para su funcionamiento. Como bien expresa Guzmán:

"De este modo las infracciones serán terminantes y manifiestas, cada uno conoce sus funciones, y nadie tiene esa autoridad deforme, que por un ejercicio arbitrario, compromete las acciones ajenas, las confunde y llena de tinieblas a la sociedad. Sobre todo, los altos poderes, que manejan enormes intereses, son de la primera necesidad que tengan sus grandes diques que los contengan: sin ellos, se precipitan sobre la sociedad en torrentes que lo arrasan todo. Cuando el poder judicial no está ceñido a aplicar leyes existentes, en su tenor expreso; cuando puede interpretarlas o llenar su vacío; es un poder monstruoso, que resume toda la soberanía, que suple leyes, las aplica y cumple: usurpa toda la autoridad, confunde las propiedades y asocia con el enredo y la falacia: entonces el foro pesa más que un Sultán, devora más que la anarquía, aniquila la moral y concluye por el trastorno de la sociedad: él es el déspota más abominable. Cuando el ejecutivo no tiene límites es un absoluto que lleva la carrera de Fernando, que hace sufrir a la 
nación la suerte de la España, y cuyo fin es de tal modo tenebroso, que no se alcanzan a ver los horrores y las convulsiones de su muerte. Cuando el legislativo se supone el padre de los poderes, y se atribuye toda la soberanía, no hay ambición que iguale a la suya, ni horrores que no cometa, ni más barrera para contenerlo que una revolución. La tiranía legislativa es tan cruel como jamás lo pudo ser la de Atila, y tanto más fuerte cuanto es más bello el ropaje popular con que se viste". ${ }^{38}$

\subsubsection{El poder ejecutivo complejo}

Era consciente el Libertador de la difícil tarea de diseñar un poder ejecutivo satisfactoriamente conformado, sobre todo cuando la tendencia emergente en América de esa época era a favor de proscribir toda reminiscencia monárquica, propiciar la alternancia en los gobiernos y establecer períodos presidenciales cortos; particularmente, cuando dentro de su concepción existía el convencimiento que el Ejecutivo debía ser la fuente y el motor de la fuerza pública. ${ }^{39}$

$\mathrm{Al}$ respecto, su cercano colaborador Antonio Guzmán ${ }^{40}$ escribió en 1826 al referirse al diseño de poder ejecutivo existente en América:

"[...] Se ha desnudado al poder ejecutivo de todas aquellas atribuciones que no hayan parecido indispensables a su existencia; sobre todo se ha apelado a un medio, que todos han llamado ingeniosísimo, y que pareció un verdadero hallazgo: este ha sido el de acortar todo lo posible la duración de un hombre en el manejo de la autoridad ejecutiva; así es que los presidentes de nuestras repúblicas no duran en sus destinos, sino cuatro, seis, y a lo más ocho años. De este modo se ha creído alejar todo peligro de que un hombre pueda usurpar el poder público,

38 Antonio Leocadio Guzmán; op. cit., p. 26 y ss.

39 El Libertador al presentarse ante la Convención de Ocaña decía respecto a la Carta constituyente colombiana: "Todos observan con asombro el contraste que presenta el ejecutivo, llevando en sí una superabundancia de fuerza al lado de una extrema flaqueza; no ha podido repeler la invasión exterior o contener los conatos sediciosos, sino revestido de la dictadura. La Constitución misma, convencida de su propia falta, se ha excedido en suplir con profusión las atribuciones que le había economizado con avaricia $[\ldots] »$.

40 Antonio Leocadio Guzmán; op. cit., pp. 41 y 42. 
y convertirlo en su provecho; pero Napoleón e Iturbide contradicen esta teoría. Sin embargo, es justo confesar, que generalmente el remedio evita el mal para el cual se ha aplicado, pero resta averiguar, si él mismo no es otro mal mayor el que desterróm.

Concluyendo su análisis considera que este corto período es adverso a la República: por impedir la maduración de las políticas internas y externas, impedir la experiencia gubernativa, propiciar los compromisos de los partidos condicionando sus políticas e incitar el desorden social pre-electoral.

La propuesta bolivariana para este poder, era singular: un Presidente vitalicio, irresponsable e inviolable, un Vicepresidente a cargo de la administración y con derecho a sucesión y cuatro Secretarios de Estado (ministros) ejecutores de las políticas de gobierno, logrando teóricamente una estructura colegiada.

La presencia de la figura de la Presidencia vitalicia en la Constitución impregnó imperecederamente su debate, con tal fuerza que la propia Carta terminó siendo conocida con la denominación equívoca de Constitución vitalicia y en su tiempo, sus partidarios fueron denominados, como "los vitalicios", sin que su impacto negativo pudiera ser atemperado por la declaración que la propia Carta hacía en el sentido que el Perú no puede ser patrimonio de ninguna persona ni familia (Art. $2^{\circ}$ ).

El Presidente debía ser nombrado la primera vez por el Congreso pleno, llamando al cuerpo legislativo y en lo sucesivo era vitalicio con facultad para designar sucesor. ${ }^{41}$

El Vicepresidente elegido por el Presidente con aprobación del cuerpo legislativo, compartía la responsabilidad ministerial y sucedia formal-

41 Contrariamente a lo que ordinariamente se afirma, la preferencia por la figura de la Presidencia vitalicia en Bolívar no viene desde 1825 sino desde 1819 cuando plantea en su Carta de Jamaica para el Gobierno de Nueva Granada "Su gobierno podrá imitar al inglés; con la diferencia de que en lugar de un rey habrá un poder ejecutivo electivo, cuando más vitalicio, y jamás hereditario, si se quiere república; una cámara o senado legislativo hereditario, que las tempestades políticas se interponga entre las olas populares y los rayos del gobierno, y, un cuerpo legislativo, de libre elección, sin otras restricciones que las de la cámara baja de Inglaterra. [...] Como ésta es mi patria tengo un derecho incontestable para desearle lo que en mi opinión es mejor». (Graciela Soriano; op. cit., pp. 79 y 80). 
mente a su elector. La participación del cuerpo legislativo con su atribución negativa o veto temporal a la nominación no era precisamente activa ya que si el candidato era rechazado sucesivamente, el Presidente presentaría segundo y hasta tercer candidato, luego de lo cual, las Cámaras ineludiblemente debían elegir, a pluralidad absoluta y dentro de las veinticuatro horas, entre los tres candidatos propuestos.

Por vez excepcional en nuestro constitucionalismo, el Vicepresidente posee funciones efectivas originarias de gobierno pues es el Jefe del Ministerio (Art. 88 $8^{\circ}$ y manda a los cuatro secretarios de Estado, siendo también delegado del Presidente ya que despacha y firma a nombre de la República y del Presidente todos los negocios de la administración con el secretario respectivo (Art. 90 ${ }^{\circ}$. Donde la conformación de esta figura dificulta su concreción, a la manera de los primeros ministros de ciertos regímenes monárquicos o de gobiernos parlamentarios, es en hacerlo depender del Presidente, quien lo puede separar por sí sólo sin expresión de causa (Art. $83^{\circ}$ inciso 3).

El cercano colaborador de Bolívar, Antonio L. Guzmán ${ }^{42}$ expone con claridad que la intención de crear esta figura constitucional era

42 Antonio L. Guzmán expresa «El Vice-Presidente puede ser considerado como un candidato, escogido por el Presidente, aprobado por la representación nacional y que todavía se expone a la vista de la nación, rodeado de negocios y peligros, para que en el desempeño de todas las funciones del supremo mando Ejecutivo, pruebe su idoneidad y desenvuelva sus talentos y su corazón a los ojos de toda la sociedad. En esta terrible escuela, respondiendo sólo por todos los actos de la administración, hecho el objeto de la atención pública, con el peso de la prensa en sí, a la frente de empleados que ha nombrado el pueblo, inspeccionado por la representación y levantado el brazo formidable de los Censores, que ninguna influencia puede contener; este hombre por el espacio de muchos años se ve corregido y aprende en el manejo de los negocios de la ciencia del Gobierno. Durante este término responde de todos los abusos y de todos los errores y la sociedad tiene el poder de separarlo de su puesto, por las fórmulas constitucionales, si se hiciere indigno de ocuparlo. Jamás se ha elevado al mando un hombre que haya sufrido tantas pruebas. ¡Cuánto dista esto de los sistemas conocidos entre los hombres! ¡Qué, diferencia, entre el Vice-Presidente de Bolivia y un príncipe inexperto y joven, que sube al trono porque su padre estuvo en él; o un candidato republicano, levantado por la fuerza de un partido, en medio de la agitación de la sociedad! En un extremo, sube un hombre al mando porque sus abuelos lo usurparon; en el otro, en medio de la fermentación de las pasiones y del choque de los intereses y de los partidos, la astucia, el influjo, el dinero, la casualidad y rara vez la razón imparcial, levanta un ciudadano inexperimentado para entregarle las llaves de la sociedad, el archivo de sus secretos y la dirección de sus intereses. 
consagrar un «candidato a Presidente en prueba permanente de idoneidad con derecho a sucesión de escuela y no por consanguinidad» a diferencia de los príncipes inexpertos que suben al trono por herencia y de los presidentes democráticos que son candidatos republicanos inexpertos en asuntos públicos levantados por las fuerzas de un partido y en medio de la agitación, intereses, pasiones, y fracciones sociales. Sentenciando que bajo este modelo, sólo accederá a la más alta magistratura del país quien ha aprendido en la escuela del Presidente anterior, es aprobado por la sociedad y resulta comprobada su idoneidad.

La administración pública quedaba en manos de los Secretarios de Estado (ministros, según la versión boliviana) quienes actuarían bajo las órdenes del Vicepresidente, firmando y asumiendo responsabilidad por todas las órdenes que autoricen; y estaban sujetos a la fiscalización de los censores y a la vigilancia de los demás funcionarios, incluyendo el poder electoral. Preveía también, la Carta que estos secretarios debían dar cuenta anualmente de su conducta y de los gastos ante el legislativo.

La propuesta innovadora de esta Constitución ha sido calificada diversamente, primero como una monarquía constitucional (por estudiosos como Gil Fortoul y Buchet de Martigny ${ }^{43}$ ) pero sin ser la calificación más justa debido a la inexistencia de la facultad hereditaria de

¡Cuánto hay que temer de un Príncipe hereditario! ¡Cuánto hay que temer de un candidato popular! Pero en Bolivia todo se hace por un sistema de naturaleza, para el bien de sus individuos. A los 30 años de una vida sin mancha, en que como Ciudadano público y privado ha cumplido un hombre con sus deberes, es elegido por el gobierno y por la nación a un tiempo, no para tomar el timón del Estado, sino para que ayudando a su piloto, pruebe sus talentos, su actividad y sus buenos principios. Después de mucho tiempo y después de una escuela que no tiene ejemplo, es que este Candidato sube al rango de magistrado supremo; llevada la aprobación de su antecesor y la sanción de la sociedad» (op. cit., pp. 45 y 46).

43 Sin embargo, como dice Víctor Andrés Belaunde: «La Presidencia vitalicia se diferencia en realidad de la monarquía en que además del principio de la herencia natural, en que ésta se basa, media otro concepto de las relaciones entre el monarca y la nación y sobre todo la existencia de una variada y fuerte jerarquía social. [...] pero aunque ello no fuera precisamente la monarquía, iba a suscitar en un medio, ya ganado a la fe democrática, la misma resistencia que el principio monárquico. La oposición adquiriría una nueva bandera más peligrosa y eficaz que la que esgrimió contra el Senado Hereditario y tenía que desarrollarse, como reacción natural, la tendencia inconveniente hacia la corta duración del Poder Ejecutivo». (op. cit., p. 183). 
orden natural para transferir los títulos. También ha sido calificada por André Marius como la constitución de la herencia sociocrática refiriéndola a la tesis de Comte sobre la conveniencia de transmitir poderes públicos mediante una modalidad hereditaria que no se base en el nacimiento sino en la elección. Pero, existe consenso en que la propuesta se aproxima mas bien a la idea del cesarismo (afirmada por juristas como Fraga Iribarne, V. A. Belaunde y Parra Pérez) basado en la opinión pública, la veneración nacional y la moralidad. Si de calificativos se trata, convendría recordar que el propio Bolívar dirigiéndose a Santander denominaría a este diseño como la de un «rey constitucional con poderes bien demarcados" (Carta de 23 de junio de 1826).

La idea de vitalicidad en los cargos públicos que Bolívar sostiene durante largo tiempo y caracteriza a su propuesta de Presidencia de la República y a los miembros de la Cámara de Censores, reposa en la observación que realiza de la crisis y turbulencia inherentes a los procesos electorales, donde se agudizan contradicciones, la sociedad se facciona y la inestabilidad se apodera de las jóvenes naciones. Por ende, dentro de su concepción, desea evitar estos vicios periódicos, mostrándonos con esta manera de enfocar la situación, la raíz republicana pero no plenamente democrática ni totalmente liberal ${ }^{44}$ de su pensamiento en esta época, puesto que como el mismo mencionaba:

«[...] gobierno democrático absoluto es tan tirano como el absolutismo. Por lo tanto, sólo podrá haber libertad bajo un gobierno templado "¡cómo queréis que yo atempere una democracia si no es con una institución aristocrática?" (Carta a Guillermo White de 26 de mayo de 1820 , refiriéndose a la creación del senado hereditario en su Constitución de Angostura)».

Mas bien intenta atraer a su modelo la característica de las monarquías que les brinda estabilidad y unidad, que por lo demás era el modelo predominante en este momento de la historia en la mayoría de Estados influyentes del mundo, ya que sólo en Suiza, Estados Unidos y algunas de las nacientes repúblicas americanas (en proceso) existían propuestas

44 En su carta del 20 de marzo de 1827, Bolívar dice al General David O'Leary: "Los que se han creado en la esclavitud, como hemos sido los americanos, no sabemos vivir con simples leyes y bajo la autoridad de principios liberales». 
democráticas, que aún no habían mostrado su eficiencia. Perspectiva temporal que es indispensable tomar en cuenta para enjuiciar este planteamiento bolivariano. ${ }^{45}$

Para equilibrar la perdurabilidad del Presidente, se planteó la necesidad de limitar sus facultades, llegando Bolivar a decir en su célebre discurso de presentación que «le había cortado la cabeza para que nadie tema a sus intenciones y le han ligado las manos para que a nadie dañe», mediante su no intervención directa en la administración interna de los asuntos ordinarios, en el nombramiento de autoridades representativas del gobierno unitario ni en las del Poder Judicial así como sus limitaciones a favor de la libertad y seguridad individual. Si bien existía este desprendimiento en cuanto a asuntos de política interna, la Presidencia mantenía con exclusividad funciones apropiadas para el plan americanista y bolivariano, tales como, las facultades sobre las declaraciones de paz y de guerra, las relaciones exteriores y la hacienda nacional.

Pero con todo, las limitaciones impuestas a la institución presidencial -según Belaunde, en un análisis contrafáctico sobre su eventual implantación- hubiesen derivado o bien en un peligro por el debilitamiento que se propiciaba en el Gobierno Central si acaso se afirmara la independencia de los electores o bien, en el supuesto contrario, hubiese proyectado la sumisión de las autoridades al poder, si Bolívar mantuviera influencia en los colegios electorales.

\subsubsection{El poder legislativo tricameral}

Tributando a la inspiración de Sieyés y a la Constitución napoleónica, el poder legislativo reposaba en tres Cámaras, pero otorgando y distri-

45 «[... Pero no puede remitirse a duda su acentuación democrática y su fundamento moral. Es fácil poner en tela de juicio la vocación democrática de Bolívar cuando se borra la perspectiva histórica dentro de la cual gestó su obra. No hay que olvidar que la democracia moderna apenas si acababa de nacer, puede afirmarse que surgía coetáneamente con Bolívar. Apenas si se estrenaba. ¿Dónde había una experiencia secular que la afianzara plenamente e indicara su eficacia? Era la nebulosa inicial a excepción de Inglaterra donde la monarquía se ensamblaba en ella y de Estados Unidos de Norteamérica, donde surgió revolucionariamente en 1776, [...] Han transcurrido dos siglos de las grandes revoluciones que sembraron la democracia y apenas ha producido uno que otro fruto sazonado [...]» Alfonso García Isaza; "Ética y democracia en el pensamiento bolivariano", p. 93. 
buyendo funciones distintas: de tribunos, senadores y censores, con veinticuatro integrantes cada una, durante los veinte primeros años. Los tribunos debían durar cuatro años; los senadores, ocho; mientras que los censores eran cargos de duración vitalicia mas no hereditarios.

Correspondían al Tribunado las atribuciones de las cámaras populares sobre asuntos con mayor proximidad al interés de la comunidad fundamentalmente en materias hacendaria, política, obras públicas, ejército, marina, asuntos extranjeros, iniciativa de reforma de la Carta y nacionalidad; teniendo por la misma norma una composición de gente más joven y por ende, con proclividad a la acción directa vehemente. Al Senado, compuesto por personas intermedias entre los tribunos y los censores, compete las legislaciones judicial, civil y eclesiástica y la nominación de funcionarios a pedido de cuerpos electorales. Finalmente, a los Censores, corresponde la instrucción y la fiscalización política y moral.

Dentro del pensamiento de Bolívar, esta composición era necesariamente armoniosa entre sus partes pues:

"[...] no se hallará siempre dividido por falta de juez árbirro, como sucede donde no hay más que dos Cámaras. Habiendo aquí tres, la discordia entre dos contrarios queda resuelta por la tercera; y la cuestión examinada por dos partes contendientes, y un imparcial que la juzga; de este modo ninguna ley útil queda sin efecto, o por lo menos, habrá sido vista una, dos y tres veces, antes de sufrir su negativa. En todos los negocios entre dos contrarios se nombra un tercero para decidir, y ¿̇o sería absurdo que en los intereses más arduos de la sociedad se desdeñara esta providencia dictada por una necesidad imperiosa?». ${ }^{46}$

Como bien afirma Villarán:

«[...] las fuerzas políticas del Senado y de la Cámara de censores preponderaban sobre la corriente popular representada por los tribunos. Aquellas cámaras tenían afinidades naturales: el censor vitalicio armonizaba probablemente con el senador elegido por ocho años y aportaba al acuerdo su tendencia conservadora, ligado a cierto orden de intere- 
ses sociales. Como la mayoría de las leyes, y desde luego en la más interesante y condenciosa (sic), la disidencia había de producirse entre los tribunos y senadores, la decisión final de estas graves cuestiones de estado tocaba a los censores; la organización legislativa, estaba pues, calculada para la supremacía a los elementos representativos de lia tradición y el orden».4?

Así, la Cámara de Censores recibía la herencia del Poder moral propuesto por Bolívar en Angostura pero sobre todo incorporaba un elemento conservador que equilibraría los procesos a cargo del Congreso con calidad definitoria.

\subsubsection{El poder judicial independiente}

La sección que la Carta de Bolívar depara para el Poder Judicial muestra un conjunto de singularidades que bien le cabe la calificación de la más fructífera para el constitucionalismo positivo peruano, de todas sus secciones. En ella se congregan: la consagración de la independencia del poder judicial del poder ejecutivo ${ }^{48}$, su origen y control popular, la estabilidad de los cargos judiciales, la creación de jurados, la intención sistematizadora del ordenamiento jurídico al disponer la elaboración de Códigos en materia civil, criminal, de procedimientos y de comercio a cargo de la Cámara de Senadores que implicaban la modernización de la Justicia, la obligación de conciliación previa, la atribu-

47 Manuel Vicente Villarán; Páginas escogidas, p. 27.

48 Esta posición de Bolívar contrasta con el planteo que hará en 1828 ante la Convención de Ocaña, donde afirmaba como inconveniente la preponderancia del Poder Judicial. Ahí decía que «No se ha visto en nación alguna entronizada a tanta altura la facultad de juzgar como en Colombia. Considerándose el modo con que están constituidos entre nosotros los poderes, no puede decirse que las funciones del cuerpo político de una nación se reducen a querer y a ejecutar su voluntad. Se aumentó un tercer agente supremo, como si la facultad de decidir las leyes que convengan a los casos, no fuese la principal incumbencia de la ejecución. Para que no influyese indebidamente en los encargados de decidirlo, los dejaron del todo inconexos con el ejecutivo, de que son por su naturaleza parte integrante; y a pesar de que se encargó a éste velar de continuo en la pronta y cumplida administración de justicia, se le cometió el encargo sin proveerle de medios para descubrir cuando fuese oportuna su intervención, ni declararle hasta qué punto pudiese extenderse. Aún la facultad de elegir, entre personas aptas, se le ha coartado [...]». 
ción directriz a la Corte Suprema, el juzgamiento público de causas criminales, juicios por jurados, abolición de recurso de injusticia notoria, de la confiscación de bienes, de la confesión del reo.

El Título VII dedicado al poder judicial inicia con la declaración de principio que los «tribunales y juzgados no ejercen otras funciones que la de aplicar leyes existentes»; definición negativa a través de la cual aparece la tesis francesa sobre la jurisdicción, tan en boga en aquella época. Esta concepción estaba dirigida directamente a evitar la denominada -tanto Bolívar en su mensaje al Congreso boliviano como por Antonio Guzmán en su exégesis- "tiranía judicial» que significa un poder judicial no ceñido a aplicar el tenor expreso de las leyes existentes; involucraba vedar el ejercicio de una interpretación judicial creativa, la subsanación de lagunas o defectos de la ley ${ }^{49}$, e imposibilitando cualquier desarrollo futuro de la revisión judicial de las disposiciones normativas.

En cuanto al origen de los magistrados este apartado del proyecto se aleja de la Carta de Napoleón considerando la nominación de magistrados mediante procedimientos distintos a la nominación a cargo del Poder Ejecutivo, haciendo participar al pueblo en la iniciativa según los requisitos de edad, conducta y versión que contempla la Carta y reposando en el Legislativo la elección entre los propuestos. Su propuesta que representa un avance se aparta del antecedente de nuestra Carta de 1823 y no ser considerado en la de 1828 , la misma que otorga su selección al Poder Ejecutivo.

Contempla la conciliación judicial como fase ineludible para los procesos civiles y penales de acción privada, con la finalidad de instituir un «medio (por él) que mueran al nacer gran parte de los pleitos ruinosos, que concluyen con la fortuna de los Ciudadanos». Con ella, profundiza la tímida disposición que sobre el particular contenía la Carta de 1823 y retomar luego la Carta de 1828 , representando un instrumento perfeccionista y pedagógico propuesto por Bolívar a favor de la sociedad.

49 La Carta establecía que ante los defectos o lagunas de la ley correspondía a la Corte Suprema "oír las dudas de los demás tribunales sobre la inteligencia de alguna ley y consultar al Ejecutivo para que promueva la conveniente declaración en las Cámaras" (Art. $105^{\circ}$ inciso 8). 


\subsubsection{El poder electoral para la elección de segundo grado}

Coincidiendo o siguiendo la propuesta de Sieyés, entre las cuatro secciones del ejercicio del poder público Bolívar ubica al poder electoral, como sistema representativo de segundo grado. Consistía en la facultad permanente de todos los ciudadanos para escoger una persona por cada diez quien se congregará al inicio del año con sus pares en el cuerpo electoral para:

- Llevar el registro electoral,

- Calificar a los ciudadanos,

- Nombrar a los miembros de las cámaras,

- Proponer candidatos:

- al ejecutivo, para los cargos de prefecto, gobernador y corregidores.

- al prefecto, para los cargos de alcaldes y jueces de paz.

- al senado, para los cargos judiciales de la circunscripción.

- Ejercer la facultad de representación de los ciudadanos que ejerzan su derecho de petición, ante cualquier autoridad particularmente ante las cámaras.

- Realizar el escrutinio para las elecciones populares y proclamarlos nombrados constitucionalmente.

Este nuevo poder representaba una intervención preponderante de las provincias y en general de la población en las decisiones principales del Estado, lo que consideraba el Libertador una recepción del modelo federal: «los colegios electorales de cada provincia representan las necesidades de los intereses de ellas y sirven para quejarse de las infracciones de las leyes y de los abusos de los magistrados. Me atrevería a decir, con alguna exactitud, que esta representación participa de los derechos que gozan los gobiernos particulares de los estados federados".

La intención era, recordando la democracia griega y compartiendo nociones de la Constitución francesa ${ }^{50}$, que la soberanía nacional representada por un diezmo de la ciudadanía peruana en cada provincia

50 En su estudio Víctor Andrés Belaunde analiza con detalle que en este tema la relación con la Constitución francesa no es de recepción sino adaptación del modelo por el Libertador, en cuanto a las funciones de los Cuerpos electorales, condiciones para alcanzar la ciudadanía, entre otros. 
cobre acción por breve tiempo una vez al año para ejercer sus funciones decisorias y electorales.

Esta presencia, de ser efectiva, estaba pensada para cubrir el espacio de acción política que operaba en los Consejos municipales y evitaba los problemas de las elecciones populares directas que tanto criticaba Bolívar.

Funcionando de esta manera, los Colegios electorales aparecerían como verdaderas asambleas provinciales de corta actividad y automática operatividad, pero por su naturaleza se convertirían -como dice Maurius- en una oligarquía de electores privilegiados, dueños de la administración provincial y común, legitimados para participar de manera activa en el gobierno de la nación. Este modelo de representatividad no era censatario pero por su propia naturaleza tenía como efecto tolerar o consolidar la aristocracia provinciana.

3.2.8 El poder moral en el pensamiento bolivariano y la pedagogía para la libertad

Simón Bolívar era consciente de la ignorancia y escasa preparación moral de las grandes masas en las sociedades americanas y del peligro que eso representaba, no sólo para la libertad que tanto había logrado conseguir sino también para el comportamiento republicano de las nacientes repúblicas $^{51}$. En esas condiciones el autogobierno debía compatibilizarse con el perfeccionismo moral del pensamiento bolivariano.

Tal situación permitía su facilidad para caer en tentaciones, la proclividad a la perversión y su condición intrínseca para ser pasto de líderes que sólo utilizaban la muchedumbre en su favor. Fue una brega de la cual testimonian muchas cartas y proclamas de todos los tiempos y a todos los destinatarios. Su espíritu perfeccionista y profundamente moralista hizo que pusiera al servicio de su causa la ocasión constitucional, planteando este ideal.

Durante los debates de Angostura en 1819 presentó su tesis del cuarto poder del Estado: el poder moral, compuesto por cuarenta miem-

51 En 1820 escribía: "Yo tengo muy poca confianza en la moral de nuestros conciudadanos, y sin moral republicana no puede haber gobierno libre. Para afirmar esta moral he inventado un cuarto poder, que críe los hombres en la virtud y los mantenga en ella» (Vicente Lecuna; Obras Completas Tomo I. La Habana 1947, p. 442). 
bros y un presidente, con la finalidad de ejercer una autoridad plena e independiente sobre las costumbres públicas y sobre la educación, organizando de alguna manera la opinión pública. ${ }^{52}$

Para cumplir con su misión se desdoblaba en dos cámaras: la de moral y la de educación que debían ser elegidos de modo original por el Congreso entre los padres de familia virtuosos que se hayan distinguido en la educación de sus hijos y en ejercicio de virtudes públicas. Quienes lo conformaban lo hacen por tiempo indeterminado (Art. 10 ${ }^{\circ}$ ) pudiendo ser destituido sólo por su propio cuerpo (Art. $11^{\circ}$ ) ante la comisión de cualquier hecho que les haga desmerecer en la veneración pública (Art. $12^{\circ}$ ).

Entre las funciones que correspondían a las cámaras reunidas, se planteaban (Art. $16^{\circ}$ ):

- Ejercer su autonomía administrativa, designando a su presidente, secretarios y autoridades.

- Distribuir en acto público premios cívicos anualmente a los ciudadanos que se hayan distinguido en virtud y patriotismo.

- Declarar eminente, virtuoso o héroe a quienes lo hayan merecido, sin el cual ninguna autoridad podrá erigir monumento o estatua a persona distinta.

- Pregonar con oprobio a los viciosos y los actos de corrupción e indecencia.

Por su parte, correspondía en exclusiva a la Cámara moral dirigir la opinión moral de la República, castigar los vicios con el oprobio y la infamia, premiar las virtudes públicas con los honores y la gloria, teniendo como única vía para ejecutar su criterio a la opinión pública y no la prohibición (Art. $1^{\circ}$ de la Sección Segunda), llevando un registro de las personas que se distinguen en el ejercicio de las virtudes públicas o en la práctica de los vicios, debiendo las demás autoridades públicas consultar este listado para proceder a las nominaciones en cargos públicos. Están sujetos a esta cámara los actos del gobierno, los funciona-

52 Para conocer en toda su extensión este planteamiento bolivariano puede leerse con provecho a J. J. Cordero Ceballos, "Bolívar y la vigencia del poder moral», donde incluye como apéndices el texto del proyecto original. 
rios públicos y los medios de comunicación mediante la censura pública posterior.

A la Cámara de educación se reservaba la organización del sistema educativo, dictar los planes de educación, elaborar una relación de instructores públicos, generar las instrucciones necesarias para promover la educación, publicar la traducción de las obras extranjeras más propias para la ilustración de la nación, llevar estadísticas sobre los avances en la instrucción de la nación, entre otras.

Afirmaba el Libertador frente a la Asamblea constituyente boliviana:

"[...] Meditando sobre el modo efectivo de regenerar el carácter y las costumbres que la tiranía y la guerra nos han dado, me he sentido en la audacia de inventar un poder moral, sacado del fondo de la obscuridad de la antigüedad, y de aquellas olvidadas leyes que mantuvieron, algún tiempo, la virtud entre los griegos y romanos. Bien puede ser tenido por un cándido delirio mas no es imposible, y yo me lisonjeo que no desdeñarais enteramente un pensamiento que mejorado por la experiencia y las luces, puede llegar a ser muy eficaz».

Complementando esta preocupación constante del Libertador, podemos apreciar el mensaje del Libertador en su discurso de Angostura:

"Tomemos de Atenas su areópago y los guardianes de las costumbres y de las leyes; tomemos de Roma sus censores y sus tribunales domésticos; y haciendo una Santa Alianza de estas instituciones morales, renovemos en el mundo la idea de un Pueblo que no se contenta con ser libre y fuerte, sino que quiere ser virtuoso. Tomemos de Esparta sus austeros establecimientos, y formando de estos tres manantiales una fuente de virtud, demos a nuestra República una cuarta potestad cuyo dominio sea la infancia y el corazón de los hombres, el espíritu público, las buenas costumbres y la moral Republicana. Constituyamos este areópago para que vele sobre la educación de los niños, sobre la instrucción nacional, para que purifique lo que se haya corrompido en la República; que acuse la ingratitud, el egoísmo, la frialdad del amor a la patria, el ocio, la negligencia de los ciudadanos; que juzgue de los principios de corrupción, de los ejemplos perniciosos, debiendo corregir las costumbres con penas morales, como las leyes castigan los delitos con penas aflictivas y no solamente lo que las ataca sino lo que las burla; no solamente lo que las ataca sino lo que las debilita; no sola- 
mente lo que viola la constitución sino lo que viola el respeto públicom. 53

De aprobarse esta innovación genial pudo convertirse en la:

«funesta inquisición moral [...] que habría contribuido a la desunión, por la constante vigilancia de unos sobre otros, empeñados en ver siempre la paja en el ojo ajeno, habría fomentado la desconfianza [...] a quien todos verían como peligro para la libertad y posibilidad de agresión para el fuero interno de los ciudadanos [...]". ${ }^{54}$

Pero de haber sido aprobado habría sido en su época un símbolo de la verdad fundamental que no pueden existir instituciones políticas, organización gubernativa ni constitucional, máxime para las nacientes repúblicas, sin bases éticas, tal como lo aprecia Belaunde al comentar esta propuesta. La alternativa entre la tolerancia moral a que invita el liberalismo y el perfeccionismo pedagógico del moralismo, Bolívar optó por esta última consciente dentro del realismo que impregnó su pensamiento.

Bajo el argumento del necesario análisis complementario de los sabios es que el constituyente de Angostura relegó el debate de este proyecto y no fue incorporado al texto final. Quizá el poder moral es la expresión más genuina de la ideología bolivariana y por ello lo veremos de una u otra forma presente, aunque progresivamente diluida, en las constituciones que proyectó durante su vida y, particularmente en la Constitución peruana de 1826 bajo las funciones asignadas al Senado conservador. Lamentablemente el proceso seguido a partir de la Independencia americana se sustentó en cuestionables bases éticas de la sociedad.

\subsubsection{Estructura centralista del poder público}

Desde el mismo inicio del pensamiento político de Bolívar apreció como crítica al federalismo, su propensión a la dispersión, lo cual a su

53 Hernández Sánchez-Barba; op. cit., p. 240 y ss.

54 Luis Beltrán Prieto Figueroa: El magisterio americano de Bolívar. Ediciones Arte, Caracas, 1986; p. 95. 
criterio no constituía sino una forma amable de regularizar la anarquía de las expectativas locales y regionales, perturbadoras de la unidad organizativa que requerían las naciones americanas en germinación. En efecto apreciando las debilidades del federalismo, Bolívar calificaba en su célebre discurso a la Convención de Ocaña, a esta forma de gobierno como una forma social constitutiva de:

«una anarquía regularizada, o más bien, es la ley que prescribe implícitamente la obligación de disociarse y arruinar el Estado con todos sus individuos $[\ldots]$ ".

En concordancia con esta línea de pensamiento y en lo que califica V. A. Belaunde como el más grande error de la Constitución boliviana, la propuesta desconocía la autonomía a nivel de los gobiernos locales, confiando por entero los asuntos a las autoridades políticas representativas del Gobierno central: prefecto, sub-prefecto, gobernador, alcaldes y jueces.

La propuesta original acogida en Bolivia abolía por entero todo recuerdo de los cabildos o municipalidades, sin embargo, la aprobada en Perú mantuvo la denominación del cargo de Alcalde pero reservado a otras funciones, como integrante del poder central y con un rol exclusivamente consultivo.

Dentro de este contexto es notorio que Bolívar juzgara a los niveles locales de gobierno como gérmenes del caos, lo cual si bien era constatado en la realidad, tal condición era debida no a la existencia misma de la institución sino al comportamiento imperfecto de quienes ocuparon sus puestos. En verdad, la población sentía a los Cabildos como espacios de vida política y económico propios que no pudieron ser sustituidos por la apertura participativa en asuntos del nivel central (por ejemplo, la selección decimal de miembros para el poder electoral que también planteaba la Carta).

El fundamento de este planteamiento fue convenientemente silenciado en el Discurso ante el Congreso de Bolivia, pero aparece con plena claridad en su Mensaje a la Convención de Ocaña del 29 febrero de 1828 cuando expresa a los legisladores:

"[...] Las municipalidades, que serían útiles como consejo de los gobernadores de provincias, apenas han llenado sus verdaderas funcio- 
nes; algunas de ellas han osado atribuirse la soberanía que pertenece a la nación, otras han fomentado la sedición, y casi todas las nuevas, más han exasperado que promovido el abasto, el ornato y la salubridad de sus respectivos municipios. Tales corporaciones no son provechosas al servicio a que se les ha destinado; han llegado a hacerse odiosas por las gabelas que cobran, por la molestia que causan a los electos que las componen, y porque en muchos lugares no hay siquiera con quien reemplazarlas [...]. No es raro el destierro espontáneo de algunos individuos de sus propios hogares, que todos piensan, no habría decreto más popular que el que eliminase las municipalidades». ${ }^{55}$

\subsubsection{La responsabilidad de los funcionarios públicos}

El tema de la responsabilidad es un tema recurrente en el pensamiento bolivariano como factor nuclear que se orientaba a asegurar la actuación del poder dentro de los fines prefijados por la sociedad y el constituyente, mostrando sumo interés por su consagración a nivel constitucional para dar permanencia a su exigencia, a favor de la pedagogía moral. ${ }^{56}$

Este factor no ha sido suficientemente resaltado entre los analistas nacionales, por cuanto constituye una continuidad en la ideología de Bolívar que se repite desde el Congreso de Angostura hasta el proyecto elaborado para Bolivia, pasando por la serie de disposiciones que durante el ejercicio de la dictadura aprobó en diversos países.

Con total justicia Bolívar manifestó al Congreso de Bolivia su convencimiento que [...] sin responsabilidad, sin represión, el Estado es un caos. Me atrevo a instar con encarecimiento a los legisladores, para que dicten leyes fuertes y terminantes sobre esta importante materia. Todos

55 M. Hernández Sánchez-Barba; op. cit., p. 329.

56 Por ejemplo, considerando que era necesario extirpar la dilapidación de los fondos públicos Bolívar decretó el 12 de enero de 1824, que:

"Artículo 1\$.- Todo funcionario público, a quien se le convenciere en juicio sumario de haber malversado o tomado para sí de los fondos públicos de diez pesos arriba, queda sujeto a la pena capital.

Artículo $2 \$$.- Los jueces a quienes, según la ley, compete este juicio, que en su caso no procedieren conforme a este decreto, serán condenados a la misma pena.

Artículo $3 \$$.- Todo individuo puede acusar a los funcionarios públicos del delito que indica el artículo $1 \$$. 
hablan de responsabilidad, pero ella se queda en los labios. No hay responsabilidad, legisladores: los magistrados, jueces y empleados abusan de sus facultades, porque no se contiene con rigor a los agentes de la administración; siendo entre tanto los ciudadanos víctimas de este abuso recomendara yo una ley que prescribiera un método de responsabilidad anual para cada empleado".

Para este tema, de crucial importancia en el pensamiento bolivariano la propuesta le deparó varios momentos:

Primero, un artículo de naturaleza comprensiva para toda la administración estableciendo que «los empleados públicos son estrictamente responsables de los abusos que cometieren en el ejercicio de sus funciones» (artículo $140 \$$ en el texto aprobado en Bolivia). Como considera Leocadio Guzmán esta es una verdadera garantía política ya que:

"Todos los empleados públicos, como simples agentes de la nación, son estrictamente responsables de los abusos que cometieren en el ejercicio de sus funciones; $y$ todos los bolivianos pueden reclamar el cumplimiento de las leyes y el castigo de sus infractores, o por el derecho de representación, o por el órgano de los cuerpos electorales o por medio de la prensa: todo el que puede hacer el mal responde por haberlo hecho, y todo el que puede recibirlo, tiene el derecho de pedir la responsabilidad por los medios de la leyn. ${ }^{57}$

Sin embargo, el texto final aprobado en el Perú abolió este artículo excluyéndolo del texto final consultado a los colegios electorales.

En este mismo orden de ideas que afirma la orientación del pensamiento bolivariano hacia una férrea responsabilidad y orden gubernativo, en el plano financiero-administrativo estableció a nivel constitucional que cada Secretaria de Estado «formarán los presupuestos anuales de los gastos que deban hacerse en sus respectivos ramos y rendirán cuenta de los que se hubieren hecho en el año anterior» (artículo 95§). En síntesis, la previsión bolivariana contemplaba la rendición de cuenta como instrumento fundamental para la adecuada gestión gubernativa.

Segundo, considerando que era necesario reforzar la responsabilidad de los magistrados judiciales postuló un artículo especializado para el tema cuando establecía «toda falta grave de los magistrados y jueces en

57 Antonio Leocadio Guzmán; op. cit., p. 26. 
el desempeño de sus respectivos cargos produce acción popular, la cual puede intentarse en todo el término de un año, o por el órgano del cuerpo electoral, o inmediatamente por cualquier boliviano" (artículo $102^{\circ}$ en la Carta boliviana). Sin embargo, el texto consultado finalmente a los colegios electorales fue cuidadosamente limitado para evitar la participación popular en el control a los jueces sujetándola a los propios colegios electorales, omitir quién era el encargado de hacer efectiva la responsabilidad de la Corte Suprema y sujetar toda acción correctiva al Gobierno. ${ }^{58}$

Tercero, en otra precisión necesaria -según el criterio bolivarianoenfatizó la responsabilidad de los agentes a cargo del orden interno cuando precisó que cualquier exceso que los prefectos, subprefectos, gobernadores, jueces de paz y alcaldes cometieran puede ser comunicada mediante acción popular. Dicha previsión fue acogida uniformemente en Bolivia (Art. 139 ) y Perú (Art. 133 ).

Aun cuando se trata de responsabilidad políica y no estrictamente de responsabilidad jurídicamente formalizada, dentro de este mismo apartado es conveniente analizar el régimen de responsabilidad reservada para las autoridades máximas del ejecutivo (presidente, vicepresidente y ministros). La propuesta que motivó una de las criticas más fuertes al proyecto consistía en exonerar a la Presidencia vitalicia de la responsabilidad por los actos de administración:

«Artículo $80^{\circ}$.- El Presidente de la República es el Jefe de la administración del Estado, sin responsabilidad por los actos de dicha administración”.

De tal modo, la responsabilidad de gobierno se hacía recaer en la Vicepresidencia quien era el activo administrador de los negocios del Estado:

$58 \mathrm{La}$ Constitución de 1826 contemplaba ello en los artículos $99^{\circ}$ y $100^{\circ}$ :

Artículo $99^{\circ}$.- Los magistrados y jueces no pueden ser suspendidos de sus empleos sino en los casos determinados por las leyes; cuya aplicación, en cuanto a los primeros, corresponde a la Cámara de Senadores, y a las cortes del distrito en cuanto a los segundos, con previo conocimiento del Gobierno.

Artículo $100^{\circ}$.- Toda falta grave de los Magistrados y Jueces en el desempeño de sus respectivos cargos produce acción popular, la cual puede intentarse en todo el término de un año por el órgano del Cuerpo electoral». 
"Artículo $88^{\circ}$.- El Vicepresidente de la República es el Jefe del Ministerio.

Artículo $89^{\circ}$.- Será responsable, con el Secretario del despacho del departamento respectivo, de la administración del Estado.

Concurrían también en la responsabilidad, los Secretarios de Estado como jefes o directores de las actividades gubernativas sectorizadas:

"Artículo 94\%.- Los secretarios del despacho serán responsables, con el vicepresidente, de todas las órdenes que autoricen contra la Constitución, las leyes y los tratados públicos».

Consciente que estamos frente a un tema controvertible y contradictorio con el principio de responsabilidad general que siempre había proclamado en la propia Carta para los demás agentes públicos, Bolívar se cuidó de no atraer la atención pública sobre ello en su mensaje al Congreso de Bolivia. Sólo con posterioridad abordaría el tema públicamente en su Mensaje a la Convención de Ocaña con motivo del cambio de la Carta colombiana que, entre otros aspectos, sí contemplaba la responsabilidad presidencial por actos de gobierno. Apoyado en su reiterado realismo como técnica constitucional expuso:

«[...] Debo decirlo: nuestro gobierno está esencialmente mal constituido. [...] No están reducidos a estos vicios de la constitución con respecto al ejecutivo. Rivaliza en entidad con los mencionados, la falta de responsabilidad de los secretarios del despacho. Haciéndolo pesar exclusivamente sobre el jefe de la administración, se anula su efecto, sin consultar cuanto es posible la armonía y el sistema entre las partes, y se disminuyen igualmente los garantes de la observancia de la ley. Habrá más celo en su ejecución, cuando con la responsabilidad moral obre en los ministros, la que se les imponga. Habrá entonces más poderosos estímulos para propender al bien. El castigo que por desgracia se llegara a merecer, no sería el germen de mayores males, la causa de trastornos considerables y el origen de las revoluciones. La responsabilidad en el escogido del pueblo será siempre ilusoria, a no ser que voluntariamente se someta a ella, o que contra toda probabilidad carezca de medios para sobreponerse a la ley. Nunca, por otro lado, puede hacerse efectiva esta responsabilidad, no hallándose determinados los casos en que se incurre, ni definida la expiación". 
Como se aprecia el realismo jurídico de Bolívar en este particular caso aparta su enfoque valorativo anterior, para concluir en la irresponsabilidad presidencial basándose en lo ilusorio de su probabilidad y por su imposibilidad de hacerla efectiva. Pero este sistema inusual en su tiempo motivó las más firmes críticas de sus opositores, acusando al Libertador de pretender entronizar su propia impunidad, pues como dice Toribio Pacheco59: «el Presidente vitalicio era inviolable e irresponsable de cualquier acto de su administración; el Poder Legislativo mismo no podía, en ningún caso, tomarle cuenta de su conducta. La responsabilidad pesaba únicamente sobre el Vicepresidente, que era el jefe del ministerio, y sobre los cuatro ministros; para lo cual habría sido preciso hacer que todos ellos fuesen independientes del Presidente y capaces de obrar por sí, como sucede en las monarquías constitucionales; pues de lo contrario, es un absurdo someter al Vicepresidente y a los ministros a la voluntad del Presidente; y, sin embargo, declarar a éste inviolable y hacer responsables a los otros de actos en que tal vez sólo fueron ejecutores de órdenes superiores».

En este extremo, es realmente justificada la posición de Pacheco ya que en esta Constitución, a diferencia de su modelo inglés, el pretendido "poder neutro" designaba y separaba por sí sólo a todos los funcionarios administrativos, incluidos a los Secretarios de estado, ejercía actos administrativos, y tenía expresamente la potestad sancionadora sobre ellos; facultades que los hacían obviamente dependientes sin que se permita a la responsabilidad extender su ámbito de acción a quien mediante el uso directo o por influencia de tales factores determinará los cursos del gobierno.

\subsubsection{La religión en el pensamiento constituyente}

Como expresamos al abordar el proceso de gestación de la Carta de Bolívar y aprobación en Bolivia y Perú, ambos Estados fueron opuestos a la pretendida libertad religiosa que el Libertador proclamaba en su Discurso a Bolivia del modo siguiente:

«En una Constitución política no se debe prescribir una profesión religiosa; pues, según las mejores doctrinas acerca de las leyes funda- 
mentales, las últimas sirven de garantía a los derechos civiles y políticos. Como la religión no pertenece a ninguno de éstos, es de otra naturaleza indefinible en el orden social y pertenece al orden intelectual».

Ciertamente la influencia de los representantes religiosos en el activismo político y la fe de ambas comunidades determinaron que el proyecto pasare por el más notorio agregado de que han dado cuenta los estudiosos de la materia. Primero, en Bolivia fue incorporado el artículo $6^{\circ}$ que declaraba religión del Estado la Católica, apostólica y romana, con exclusión de todas las demás. Por su parte, entre nosotros fue incluida como religión oficial a la Católica, apostólica y romana, pero cuidándose de no excluir otros cultos (artículo 6\$) no obstante la petición de los colegios electorales a favor de la proscripción de otros cultos.

Pero, advierte con razón V. A. Belaunde que no obstante su discurso liberal, en lo operativo el proyecto revelaba un afán regalista que se percibe en el sistema administrativo de nombramiento de las autoridades eclesiásticas y en la potestad de revisión de las decisiones de la Iglesia, tendencia que fue más preponderante en el proyecto peruano que la original de Bolivia.

El proyecto boliviano sólo contemplaba como atribuciones del Presidente de la República "conceder el pase o suspender las decisiones conciliares, bulas pontificias, breves y rescriptos, con anuencia del poder a quien corresponda" (inciso 24, artículo $70^{\circ}$ ), "presentar al gobierno eclesiástico uno de la terna que le pase éste, de los candidatos propuestos por el cuerpo electoral, para curas y vicarios de sus provincias (inciso 26 , artículo $70^{\circ}$ ) y como facultades de la Cámara de Senadores proponer a la Cámara de Censores una terna de candidatos para arzobispos, obispos, dignidades, canónicos y prebendados de las catedrales, quien los eligión (artículos $47^{\circ}$, inciso 6 y $60^{\circ}$ inciso 1 ).

Por su parte, el proyecto presentado a Perú con motivo de los nombramientos torna más centralizada la fórmula ya que ahora el Presidente no sólo escogerá de la terna que le presente la Iglesia y la remitirá a ésta para su nombramiento oficial sino mas bien será él mismo quien lo elija y nombrará (artículo $83^{\circ}$ inciso 27). Tal orientación es percibida con mayor nitidez cuando agrega la facultad del Senado de presentar ante el Presidente una relación de candidatos para los cargos de arzo- 
bispados, obispados, canonjías y prebendados (artículo $49^{\circ}$ inciso 6), seguido de la elaboración por el Presidente de una terna para tales cargos y la comunica a la Cámara de Censores, quien finalmente los elegirá (artículos $60^{\circ}$ inciso 1 y $83^{\circ}$ inciso 25 ).

3.2.12 La inviolabilidad de la Constitución y previsión de los estados de excepción

La Carta ser preocupó por declarar su inviolabilidad con alcance a los propios poderes del Estado y demás autoridades gubernativas, de modo que cuando la intención fuere adversa a la norma suprema debía canalizarla mediante el procedimiento de reforma legislativa que previsoramente debía realizarse hacia 1830 .

Sin embargo, el realismo del pensamiento boliviano indujo a reconocer la necesidad de contemplar los estados de excepción otorgando cobertura constitucional a las situaciones de emergencia que no podían ser afrontados con la normalidad constitucional pensada para tiempos de orden. De tal manera, fue la primera Carta peruana que incorporó a sus textos constitucionales regulación para los estados de excepción ${ }^{60}$ bajo dos modalidades a ser declaradas por el Congreso: como suspensión de derechos ciudadanos (particularmente la garantía de libertad de tránsito prevista en el artículo $123^{\circ}$ ) y, en su versión más grave, como un estado de dictadura en el que se inviste al Ejecutivo de la suma de facultades necesarias para superar la causa para tal decisión, pero sometido a la responsabilidad por los abusos que cometiera durante este lapso.

$60 \mathrm{El}$ articulado establecía:

Artículo $30^{\circ}$.- Las atribuciones particulares de cada Cámara se detallarán en su lugar. Son generales: [...].

5. Investir en tiempo de guerra o de peligro extraordinario al Presidente de la República, con las facultades que se juzguen indispensables para la salvación del Estado. Artículo $123^{\circ}$.- Si en circunstancias extraordinarias la seguridad de la República exigiere la suspensión de algunas de las formalidades prescritas en este capítulo, podrán las Cámaras decretarlo. Y si estas no se hallasen reunidas podrá el Ejecutivo desempeñar esta misma función como medida provisional y dar cuenta de todo en la próxima apertura de las Cámaras, quedando responsable de los abusos que haya cometido. 


\section{A modo de conclusión: balance del proceso}

En su carta a Santa Cruz de 8 junio de 1827, Bolívar afirma:

«Nada me importa la Constitución boliviana. Si no la quieren, que la quemen, como dicen que ya se ha hecho antes de ahora. Yo no tengo amor propio en materias graves que pesan sobre la Humanidad».

Era el momento de la desilusión por la irremediable pérdida de un proyecto político-constitucional acariciado por el Libertador.

A ese momento se llegó por la suma de diversas circunstancias: por lo iluso de algunas de las innovaciones propuestas en la Constitución para Bolivia y Perú, por no comprender la necesaria crisis que todo inicio de cualquier república acarrea y que el Libertador pretendió evitar a toda costa, por los personalismos existentes en nuestro país a los cuales agraviaba un proyecto de estabilidad a partir de la propia persona de Bolívar y de sus sucesores, por el clima adverso que generó su acelerada imposición en vez de haber seguido la meditada búsqueda de consenso que era viable por la gran aceptación del Libertador. También contribuyeron a este resultado: un equivocado cálculo político del Libertador al sobrestimar su potencialidad para plantear su realista plan y un enfoque inadecuado de las necesidades de las sociedades nacientes que preferían la libertad y los ideales democráticos -pese a la inseguridad que para la época representaban - al orden artificial impuesto por la autoridad en vez del obtenido por la madurez social.

Las propuestas políticas del Libertador estuvieron permanentemente impregnadas de una incesante búsqueda del justo medio aristotélico, que se muestra tanto en la persecución del equilibrio entre la libertad ciudadana y el orden, como en su esfuerzo por sintetizar las características que consideraba más favorables entre las tendencias sobre el gobierno existentes en su época (monarquía, federalismo, democracia, aristocracia); congregando como sintetiza V. A. Belaunde, la estabilidad de la monarquía; el poder electoral de la democracia; la centralización hacendaria absoluta del régimen unitario; la intervención popular en los nombramientos políticos como en el federalismo; los censores vitalicios como en la oligarquía y el derecho de petición y de refrendación de las reformas constitucionales como en el sistema plebiscitario. Indudablemente, no siguió determinada corriente pues deseaba cons- 
cientemente apartarse de las tendencias monárquicas y liberal-individualista así como de los extremos peligrosos.

Esa tendencia a la síntesis, preferentemente entre aquellas características que reporten la mejor sumatoria de autoridad -representativa del orden y estabilidad- y participación -representativa de la libertadapuntalada por el perfeccionismo en su censura hacia la moral pública y el comportamiento social, fueron las líneas maestras del pensamiento constituyente de Bolívar de esta época. Intentó un esfuerzo netamente americanista y realista por regular sus instituciones mediante normas pensadas para toda la comunidad nacional y no sólo para un sector generalmente el aristocrático o capitalino-, teniendo en cuenta que las bondades de la democracia representativa aún no era una verdad comprobada en los Estados de la época, menos aún en las condiciones en que se encontraban los pueblos americanos y mientras, la monarquía había concluido su ciclo en el país pero mantenía presencia mayoritaria en Europa y otros continentes.

De acuerdo con la estratificación de la evolución del pensamiento bolivariano que plantea V. A. Belaunde la Carta de 1826 pertenece a su cuarta etapa: la del cesarismo semi-feudal y semidemocrático que aparece inmediatamente después a la cumbre del pensamiento bolivariano. Pero, desde la perspectiva del constitucionalismo peruano representa una carta cuya desestabilización temprana privó de la posibilidad de tener la influencia que debía pro la curiosa suma de características irrepetibles: ser una constitución otorgada por la autoridad del Libertador y no pactada como las demás Cartas en nuestro país; la inexistencia de antecedentes sobre la gestación de sus preceptos o exposición de motivos que permita conocer la razón esencial de su articulado, ser un proyecto constitucional típicamente proveniente de la autoridad unipersonal de un hombre de acción como Bolívar, la concentración en su estructura del poder neutro (con la presencia de la Presidencia vitalicia) con el poder conservador (en el Senado conservador) así atribuir facultades activas propias en asuntos gubernativos al cargo de Vicepresidente.

Los debates de su tiempo y los ulteriores han sido acaparados por la composición de la estructura del poder público y, particularmente la de los poderes legislativo y ejecutivo, sin percibir que también esta propuesta de texto traía al debate constitucional nacional temas importantes como la abolición de la esclavitud; la ciudadanía continental como instrumento de integración; la libertad religiosa; el establecimiento 
de deberes correlativos a los derechos; creaba las condiciones desaprovechadas para desarrollar tempranamente el hábeas corpus en nuestro país; la independencia judicial, perfecciona la conciliación como medio alternativo a la solución de conflictos (tema que recién en nuestros días es redescubierto por la legislación como instrumento útil para la descarga procesal y solución consensual de conflictos); la responsabilidad funcionarial y la rendición de cuentas como obligación de funcionarios públicos; la abolición de vinculaciones eclesiásticas; y, la consagración de los estados de excepción como forma de integrar y ordenar dentro del ordenamiento constitucional a las situaciones de emergencia que hasta esa época eran motivo de soluciones extraconstitucionales como la dictadura y suspensión de la Constitución.

Pero la utilidad del estudio de esta Carta no sólo radica en detenerse en aquellas instituciones, figuras y esquemas que fueron desaprovechadas para el constitucionalismo peruano en su oportunidad, sino por cuanto el análisis a su acelerado proceso de aprobación -irregular por cierto- y de los pronunciamientos de los colegios electorales nos informa del pensamiento vivo de los representantes de la sociedad nacional de la época, revelándosenos su intolerancia en materia religiosa, la desconfianza en los cargos reelectivos que sólo cedió ante la autoridad del Libertador, la consideración favorable a otorgar la presidencia a la persona de Bolívar incluso sin responsabilidad y con carácter vitalicio, entre otras nociones interesantes.

Mediante el pensamiento contrafáctico se puede especular acerca de si el proyecto constitucional fuera un modelo transitorio o permanente, de la sinceridad o no de sus ideas, sobre la viabilidad del esquema gubernativo tal como fue planteado, sobre si de aplicarse hubiese la República alcanzado la estabilidad deseada evitando los sucesivos relevos en la Presidencia de la República ocurridos durante le siglo pasado o cómo hubiese reaccionado la sociedad, si en vez de imponer le proyecto, Bolívar planteaba su intención mediante la modificación constitucional a la Carta de 1823 (tal como inicialmente lo consideró). Pero, en este aspecto, nos deja dos lecciones no siempre aprovechadas: la primera, para la política constitucional, sobre la inestabilidad de los proyectos constitucionales personales para el ejercicio del poder, sobre todo cuando se privilegia la autoridad por sobre cualquier otras consideraciones; y la otra, para el constitucionalismo, según el cual la vigencia real de las Cartas es fortalecida cuando reposa en el consenso, el 
debate, el sano intercambio de ideas que comprometan la conciencia social y no sólo por su refrendo popular directo o indirecto que puedan otorgar mayorías transitorias.

\section{Bibliografía}

Bákula Budge, María Cecilia

1975 Los ideales de Bolívar en la integración de los pueblos hispanoamericanos. Publicaciones de la Comisión Nacional del Sesquicentenario de la Independencia del Perú. Lima-Perú.

Belaunde, Víctor Andrés

1928 «La constitución vitalicia». En: Mercurio Peruano, Nº 117, Año XI, Volumen XVII; Marzo. Lima (Perú). Artículo aparecido como Capítulo XXI de su libro «Bolívar y el pensamiento político de la revolución americana» (Ver).

Belaunde, Víctor Andrés

1983 Bolívar y el pensamiento político de la revolución americana. Edición de Homenaje al bicentenario del nacimiento del Libertador Simón Bolívar. Quinta Edición; Lima (Perú). JOMM, Asociados S.R.L. Editores.

Brice, Angel Francisco

1959 "Constitución Bolivariana". (Separata de la Revista de la Sociedad Bolivariana de Venezuela, Volumen XVII, $\mathrm{N}^{\circ}$ 57.17 diciembre de 1958. Imprenta Nacional, Caracas (Venezuela.

Comisión Nacional del Sesquicentenario de la Independencia del Perú 1974 Colección Documental de la Independencia del Perú. Tomo XIV: Obra Gubernativa y epistolario de Bolívar. Volumen $1 \$$ (Legislación 1823-1825), Volumen $2 \$$ (Legislación de 1826), Volumen $3 \$$ (Libro de Decretos 1824), Volumen $4 \$$ (El Congreso de Panamá). Lima, Perú. 
Constitución para la República Peruana

1826 Imprenta de la Libertad por José María Masías. Lima. Edición que contiene la documentación de la época sobre la génesis de la Carta de Bolívar, incluyendo las actas de los Colegios Electorales.

Cordero Ceballos, J.J.

1988 "Bolívar y la vigencia del poder moral». Serie Estudios $N^{\circ}$ 35; Biblioteca de la Academia de Ciencias Políticas y Sociales. Academia de Ciencias Políticas y Sociales, Caracas (Venezuela).

Cóndova Mario, Luis

1983 «Bolívar y el derecho». En: Boletín del Archivo General de la Nación Nos. 244-245, enero a diciembre, Tomo LXXIII, Caracas (Venezuela).

Félix Trigo, Ciro.

1957 Las constituciones de Bolivia. Ediciones Cultura Hispánica. Madrid (España).

Fraga Iribarne, Manuel

1961 «La evolución de las ideas de Bolívar sobre los poderes del Estado y sus relaciones». En: Revista de Estudios Políticos $N^{\circ}$ 117-118, Mayo-Agosto. Instituto de Estudios Políticos. Madrid (España).

García Belaunde, Domingo

1993 Las constituciones del Perú, Textos institucionales, cuadros comparativos. W.G. Editores. Edición oficial. Ministerio de Justicia. Primera edición.

García Isaza, Alfonso

1983 «Etica y democracia en el pensamiento bolivariano». En: Revista Estudios de Derecho, Facultad de Derecho y Ciencias Políticas de la Universidad de Antioquía; Volumen XLII, N 103, Año XLIV -Segunda Epoca- Marzo. Colombia. 
GuZMÁn, Antonio Leocadio

1826 Ojeada al proyecto de Constitución que el Libertador ha presentado a la República Bolívar. Imprenta Republicana Administrada por José María Concha. Lima.

Hernandez Sánchez-Barra, Mario

1975 Simón Bolívar: Discursos, proclamas y epistolario político. Editora Nacional, Madrid (España).

Labarca Prieto, Domingo

1983 «Bolívar y la organización del Poder Público en el Discurso de Angostura». En: Revista Estudios de Derecho, Facultad de Derecho y Ciencias Políticas de la Universidad de Antioquía; Volumen XLII, No 103, Año XLIV -Segunda Epoca-. Marzo. Colombia.

Marius, André

1924 Bolívar y la democracia. Casa Editorial Araluce, Barcelona (España).

Otero, Gustavo Adolfo

1944 «Bolívar y Bentham (Génesis de la Constitución Boliviana de 1826)». En: Historia Revista de Cultura No 6, Volumen Segundo. Enero-Junio. Lima (Perú).

Pareja Paz-Soldán, José

1954 "Las Constituciones del Perú». Serie: Las Constituciones Hispanoamericanas. Publicadas bajo la dirección de Manuel Fraga Iribarne. Ediciones Cultura Hispánica, Madrid (España).

Pérez Concha, Jorge

1975 Pensamiento político de Bolívar. Colección Ariel Universal No 30. Editorial Ariel Universal, Guayaquil (Ecuador).

Petzold-Pernia, Hermann

1983 «La influencia de Benjamín Constant en el Libertador Simón Bolívar». En: Revista Estudios de Derecho, Facul- 
tad de Derecho y Ciencias Políticas de la Universidad de Antioquia; Volumen XLII, $N^{\circ} 103$, Año XLIV -Segunda Epoca-. Marzo. Colombia.

Salcedo-Bastardo, J.L.

1983 «El mundo normativo. Posición humana y ubicación conceptual». En: Revista Estudios de Derecho, Facultad de Derecho y Ciencias Políticas de la Universidad de Antioquía; Volumen XLII, N 103, Año XLIV -Segunda Epoca-. Marzo. Colombia.

SÁnchez Sánchez, Luis Alberto

1997 A Bolívar. Instituto Luis Alberto Sánchez. Primero Edición, febrero. Lima (Perú).

SORIANO, Graciela (compiladora)

1990 Simón Bolívar: escritos políticos. El Libro de Bolsillo, Sección: Clásicos, $N^{\circ} 175$. Alianza Editorial, Madrid (España). Octava reimpresión (octubre).

Townsend Ezcurra, Andrés

1973 Bolívar, Alfarero de Repúblicas. Ediciones Libera, Buenos Aires (Argentina).

Villarán, Manuel Vicente

1962 Páginas escogidas. («Ensayo sobre las ideas constitucionales de Bolívar»). Talleres Gráficos P.L. Villanueva, S.A. Lima (Perú). 